Cochrane Database of Systematic Reviews

\title{
Cognitive-behavioral treatment for antisocial behavior in youth in residential treatment (Review)
}

Armelius BÅ, Andreassen TH

Armelius BÅ, Andreassen TH.

Cognitive-behavioral treatment for antisocial behavior in youth in residential treatment.

Cochrane Database of Systematic Reviews 2007, Issue 4. Art. No.: CD005650.

DOI: 10.1002/14651858.CD005650.pub2.

www.cochranelibrary.com 
TABLE OF CONTENTS

HEADER 1

ABSTRACT

PLAIN LANGUAGE SUMMARY

BACKGROUND

OBJECTIVES

METHODS

RESULTS

Figure 1.

DISCUSSION

AUTHORS' CONCLUSIONS

ACKNOWLEDGEMENTS

REFERENCES

CHARACTERISTICS OF STUDIES

DATA AND ANALYSES

Analysis 1.1. Comparison 1 Recidivism at 6 months: CBT vs. Control, Outcome 1 Results at 6 months.

Analysis 2.1. Comparison 2 Recidivism at 12 months: CBT vs. Control, Outcome 112 months: Dropouts = Proportional.

Analysis 2.2. Comparison 2 Recidivism at 12 months: $C B T$ vs. Control, Outcome 212 months: Dropouts = None.

Analysis 2.3. Comparison 2 Recidivism at 12 months: CBT vs. Control, Outcome 312 months: Dropouts = All.

Analysis 2.4. Comparison 2 Recidivism at 12 months: CBT vs. Control, Outcome 412 months: Proportion Farrington excluded.

Analysis 2.5. Comparison 2 Recidivism at 12 months: CBT vs. Control, Outcome 512 months: Dropouts proportional excluding Guerra and Farrington.

Analysis 3.1. Comparison 3 Recividism at 24 months: CBT vs control, Outcome 124 months: Proportional.

Analysis 4.1. Comparison 4 CBT vs Alternative treatment, Outcome 1 Alternative treatment Proportional.

ADDITIONAL TABLES

WHAT'S NEW

HISTORY

CONTRIBUTIONS OF AUTHORS

DECLARATIONS OF INTEREST

SOURCES OF SUPPORT

INDEX TERMS 
[Intervention Review]

\section{Cognitive-behavioral treatment for antisocial behavior in youth in residential treatment}

Bengt-Åke Armelius ${ }^{1}$, Tore Henning Andreassen ${ }^{2}$

1Department of Psychology, University of Umeå, Umeå, Sweden. 2Faculty of Social Sciences, Regional University of Bodø, Bodø, Norway

Contact address: Bengt-Åke Armelius, Department of Psychology, University of Umeå, Umeå, 901 87, Sweden. bengtake.armelius@psy.umu.se.

Editorial group: Cochrane Developmental, Psychosocial and Learning Problems Group

Publication status and date: Edited (no change to conclusions), published in Issue 1, 2010.

Citation: Armelius BÅ, Andreassen TH. Cognitive-behavioral treatment for antisocial behavior in youth in residential treatment. Cochrane Database of Systematic Reviews 2007, Issue 4. Art. No.: CD005650. DOI: 10.1002/14651858.CD005650.pub2.

Copyright @ 2010 The Cochrane Collaboration. Published by John Wiley \& Sons, Ltd.

\section{A B S T R A C T}

\section{Background}

Cognitive-behavioral therapy (CBT) appears to be effective in the treatment of antisocial behavior both in adolescents and adults. Treatment of antisocial behavior in youth in residential settings is a challenge since it usually involves more serious behavioral problems and takes place in a closed setting. The motivation for change is usually low and there is little possibility to address the maintenance of any behavioral changes following release.

\section{Objectives}

To investigate the effectiveness of CBT in reducing recidivism of adolescents placed in secure or non-secure residential settings. A secondary objective was to see if interventions that focus particularly on criminogenic needs are more effective than those with a more general focus on cognitions and behavior.

\section{Search methods}

We searched a number of databases including: CENTRAL 2005 (Issue 2), MEDLINE 1966 to May 2005, Sociological Abstracts 1963 to May 2005, ERIC 1966 to November 2004, Dissertation Abstracts International 1960s to 2005. We contacted experts in the field concerning current research.

\section{Selection criteria}

Both randomised controlled trials and studies with non-randomized comparison groups were included. Participants had to be young people aged 12-22 and placed in a residential setting for reasons of antisocial behavior.

\section{Data collection and analysis}

Two reviewers independently reviewed 93 titles and abstracts; 35 full-text reports were retrieved and data from 12 trials eligible for inclusion were extracted and entered into RevMan. Results were synthesized using a random effects model, due to the significant heterogeneity across included studies. Results are reported at 6,12 and 24 months post-treatment, and presented in graphical (forest plots) form. Odds ratios are used throughout and intention-to-treat analyses were made with drop-outs imputed proportionally. Pooled estimates were weighted with inverse variance methods and $95 \%$ confidence intervals were used.

\section{Main results}

The results for 12 months follow-up show that although single studies generally show no significant effects, the results for pooled data are clearly significant in favor of CBT compared to standard treatment with an odds ratio of 0,69 . The reduction in recidivism is about $10 \%$ on the average. There is no evidence of effects after 6 or 24 months or when CBT is compared to alternative treatments. 


\section{Authors' conclusions}

CBT seems to be a little more effective than standard treatment for youth in residential settings. The effects appear about one year after release, but there is no evidence of more long-term effects or that CBT is any better than alternative treatments.

\section{PLAIN LANGUAGE SUMMARY}

\section{Cognitive-behavioral treatment for antisocial youth in residential care}

Results of twelve studies, five RCTs and seven non-RCTs including a control group, conducted in the USA, Canada and Great Britain suggest that Cognitive Behavioral Treatment (CBT) in residential settings is more effective than standard treatment in reducing criminal behavior in adolescents twelve months after release from the institution. The results are consistent across studies although the studies vary in quality. There is no evidence that the results of CBT are better than those of alternative treatments, i.e. treatments other than CBT. 


\section{B A C K G R O U N D}

\section{Description of the condition}

The term "antisocial behavior" can be used to mean one of a range of behaviors including violence toward people or animals, destruction of property, deceitfulness, theft and/or serious rule violations. Antisocial behavior has emerged as an important issue of concern to the legal system, to the public, to researchers and to practitioners in many countries. Many other terms like, offender, delinquent or conduct disorder are often used to describe the person or the behavior. For this review the term "antisocial behavior" was used to describe referral from a legal system for any youth who has committed a serious crime and/or offended on at least one occasion. Antisocial behavior can result in harm to other people or their property. The costs for the youth, the family and society may be large both in terms of physical and emotional harm, but also in terms of money. There has been substantial research on antisocial behavior in youth in the past twenty years, which has advanced the breadth, depth and specificity of knowledge about antisocial behavior in youth (Elliot 1998; Loeber 1998; Tolan 1994; Rutter 1998). Serious delinquency is characterized by antisocial attitudes, values, beliefs and cognitive emotional states and personality patterns like weak self control or restlessness and aggression (Cottle 2001; Simourd 1994; Heilbrun 2000; Andrews 1990). It is often preceded by antisocial behavior in early childhood, and other important correlates are antisocial friends and isolation from non-criminal others, parenting problems in the domains of affection/caring and monitoring/discipline, low levels of achievement in school or at work, little involvement in non-criminal leisure and recreational pursuits, and substance abuse (Simourd 1994; Henggeler 1996; Andrews 1998; Andrews 2006). All of these characteristics may also be used to predict antisocial behavior in the future. In any birth cohort, the incidence and prevalence of serious antisocial behavior reaches a peak during adolescence (Lipsey 1998). A very large percentage of adolescents participate in antisocial behavior of some sort which is usually not considered to be a serious crime. Only $5-10 \%$ of all who show antisocial behavior in youth continue with serious antisocial behavior in adulthood (Moffitt 1993; Patterson 1993). In fact, only about $5 \%$ of all children exhibit an early, persistent and extreme pattern of antisocial behavior. However, this small group accounts for $50-60 \%$ of all crimes committed by youth (Howell 1995; Tremblay 1999; Stattin 1991; Loeber 1997; Loeber 1998; Loeber 2000). Moffitt (Moffitt 1993) found that $86 \%$ of the children diagnosed as conduct disordered at seven, were still exhibiting these behaviors at 15 years old. It is likely that this group may receive some form of residential treatment during their adolescence. It is reasonable to expect a rate of recidivism around $45 \%$ for this group of adolescents and effective treatments may reduce this rate with about $8 \%$ (Genovés 2006).

\section{Description of the intervention}

Several approaches have been used to tackle the problem of antisocial behavior, varying from incarceration as punishment, to treatment in correctional settings, residential treatment and a variety of treatments under open care conditions such as multi-systemic therapy (MST) (Henggeler 1996) with a strong focus on the family in its social context, and Funcional Familiy Therapy (Sexton 1999) with more focus on the functioning of the family itself. Although home-based treatments like MST (Littell 2005) and FFT may appear to be more effective than residential treatments (Lipsey 2001) it is sometimes necessary to place the youth in a residential set- ting out of home. This is usually some form of institution, which allows for restrictions and control over behavior. Residential treatments may be characterized as secure or non-secure depending on the degree of control imposed on the behavior of the youth through locked doors, fences etc. Placement together with deviant peers may also have negative effects that outweigh any treatment gains and may lead to adverse outcomes for the youth (Dishion 2006). It is therefore important to study which approaches to treatment that give positive results in residential settings. Historically, there have been a variety of approaches to treatment of antisocial behavior in youth, usually with poor outcomes. However, during the last 20 years a number of reviews suggest that interventions based on cognitive behavioral therapy (CBT) may result in positive outcomes (Garrett 1985; Izzo 1990; Lipsey 1992; Antonowicz 1994; Redondo 1999; Dowden 2000; Lipsey 2001; Landenberger 2005; Genovés 2006). CBT consists of a variety of interventions designed to change cognitions and behavior. The basic idea in CBT is that thoughts, images, beliefs and attitudes are intimately related to how we behave. Therefore, it is necessary to direct interventions both to cognitive and behavioral aspects of the criminal behavior and not predominantly to behavior as in behavior therapy programs or to thoughts as in psychodynamically oriented programs. Usually, several different techniques, such as social skills training, moral reasoning, aggression management etc. are combined to form a comprehensive treatment program, addressing several of the factors that contribute to antisocial behavior. Prototypical examples of comprehensive CBT programs for offenders include Aggression Replacement Training (Goldstein 1987), Reasoning and Rehabilitation Program (Ross 1985), and Moral Reconation Therapy (Little 1988). These structured programs include training manuals for stepwise development of social skills and moral thinking that will help the person to function pro-socially.

\section{How the intervention might work}

There is some evidence to suggest that treatment programs aiming to change antisocial behavior need to focus on important variables such as the quality of the treatment implementation and the risk level of the juveniles (Andrews 2006; Landenberger 2005). In order to be maximally effective, the programs also may need to focus onthe known predictors of antisocial behavior, sometimes called criminogenic needs (Andrews 1990; Andrews 2006; Dowden 2000; Cameron 2004). Such criminogenic needs, especially criminological thinking and antisocial attitudes and values are typical not only of the individual, , but also of his social context (Henggeler 1989; Mulvay 1993; Tolan 1994). Residential programs may have difficulty to maintain and generalize changes in behavior $f$, if peers, family and school cannot be directly included in the treatment programs. For cognitive behavioral therapy it is important that the treatment includes the opportunity to rehearse new skills and behaviors in the environments where they naturally occur, i.e. in society back home. Thus, it is uncertain whether any sustainable treatment effects can be obtained in a context in which the person has been placed against his or her will and where there are very limited contacts with his or her usual environment.

\section{Why it is important to do this review}

To date, meta-analytic reviews suggest that CBT is the treatment method of choice for antisocial youth but they draw heavily on studies conducted in a mixture of open and secure, or residential, settings (Lipsey 1992, Lipsey 1998, Lipsey 1999; Izzo 1990; Andrews 1990; Dowden 1999; Dowden 2000), and include a mixture 
of adolescent and adult offenders, with different degrees of problem behavior (Redondo 1999; Dowden 2000; Lipsey 2001). Some of the meta-analyses have used broad definitions of CBT (Wilson 2000), which include traditional behavior therapy methods (e.g. token economy, contingency contracting, etc.) while others have adopted a relatively narrow definition that requires that the intervention focuses primarily on cognitive change (Lipsey 2001). The research evidence for the effectiveness of CBT in residential settings for youth remains undetermined. Of the few reviews that focus solely on residential or institutional treatment (Garrett 1985; Redondo 1997; Redondo 1999; Genovés 2006) only two (Garrett 1985; Genovés 2006) were restricted to youth. The review by Garrett 1985 included studies up to 1983 and did not have a specific focus on CBT. The review by Genovés 2006 included studies between 1970 and 2003 and only included secure institutions. The review by Lipsey 2001 is the only study with a specific focus on CBT, but this review included both juvenile and adult offenders in both institutional and non-institutional settings. The review was restricted to studies with experimental or strong quasi-experimental designs and only 14 primary studies that met the eligibility criteria were located. The most promising results were found for juvenile offenders in demonstration programs set up by researchers and applied to offenders on probation or parole i.e. not incarcerated. No research studies of mainstream programs using CBT with juvenile offenders that met the methodological standards of the review were found. Since the evidence seems to point to less favorable results for antisocial youth who are treated in institutions than in open care (Lipsey 1992; Izzo 1990; Andrews 1990), it is likely that open care will be preferred whenever possible. However, because the need for residential treatment will most likely prevail it is important to explore the possible effects of $\mathrm{CBT}$ interventions within such settings, which probably cater for the most severe cases under the most severe conditions.

\section{O B JE C T IVES}

To determine the effectiveness of CBT in residential settings for reducing criminal behaviour and other antisocial behaviour in young people. A secondary objective was to determine if a focus on criminogenic needs within CBT programs is associated with better outcomes.

\section{METHOD S}

\section{Criteria for considering studies for this review}

\section{Types of studies}

Randomised controlled trials (RCTs) and studies with other types of allocation of participants to at least two different conditions were included. In the protocol we misleadingly used the term "alternate allocation" to describe the alternatives to RCTs. For the purpose of this review, we use the term "Non-RCT" to describe studies including a treatment and a separate comparison group of any kind, where there has been no true randomization procedure. Comparison groups could be either an alternative, i.e. non-CBT treatment, a standard or usual treatment, or no intervention.

\section{Types of participants}

Young people, male or female, aged 12-22 years and placed in a residential setting to receive treatment because of antisocial behavior, whether legally adjudicated or not. Participants with co-morbid conditions, such as learning disability were included. If the study in- cluded groups of youth with different problems, it would be included if results for those with antisocial behavior were reported separately. (Post protocol, the age of participants was increased from 20 to 22 ).

\section{Types of interventions}

Studies including CBT provided in a residential setting, whether in the form of a comprehensive programme or an isolated intervention were included. Studies with behavioral interventions without a cognitive component were excluded as well as studies with a cognitive component but no behavioral component.

Residential settings include out-of-home group settings with more than two members of staff. This excluded foster homes and specialized foster homes (Treatment Foster Care) (Fisher 2000) as well as family-like interventions with several youth but only two adults, such as Teaching Family Homes (Wolf 1995). Residential settings include both secure and non-secure settings. The term "secure" means, for this review, environments or institutions characterized by physical restraint measures such as locked doors, walls, bars, fences, etc. Prison and prison-like placements were included as well as training schools and treatment programs in open or semi-open settings where there are less restrictions

Acceptable comparisons were interventions in residential settings that did not satisfy the criteria for CBT interventions as described above.

\section{Types of outcome measures}

\section{Primary outcomes}

Primary outcomes are expressions of criminal behaviour:

- Official records obtained from the police or juvenile justice records that involve any kind of court response.

- Other official records that report offences which, because of age, have not resulted in responses from juvenile justice.

- Self reports on criminal behaviour from the offender after leaving the program.

- Any new official serious registered offence that causes a new intake to a residential facility.

\section{Secondary outcomes}

Secondary outcome measures are other behavioral outcomes based on standardized tests and inventories related to variables such as

- self-control

- locus of control

- psychological adjustment

- self-esteem

- school attendance

- cognitive and social skills

- relations to pro-social friends

No study was excluded because it did not use standardized tests or measures.

Outcomes reported in studies were based on observation periods that vary in length. The goal of treatment is not changes in behaviour while the youth are in a residential setting, but lasting changes in "normal settings", after discharge from residential settings. The 
review excluded studies that only report outcome measures while the youth is in a residential setting. At least 6 months follow-up time was required and analyses were made for different follow-up periods depending on what were available.

\section{Search methods for identification of studies}

\section{Electronic searches}

In order to identify studies that met the inclusion criteria searches of electronic databases were run, authors working in this area were contacted, and references in reviews and meta-analyses were examined. Both published and unpublished works were eligible for the review. No language restrictions were applied.

The following databases were searched:

-Cochrane Controlled Trial Register (CENTRAL) searched 2005 (Issue 2)

-Medline searched 1966 to May 2005

-Campbell Collaborations Social, Psychological, Educational \& Criminological Register (C2-SPECTR) searched May 2005

-Sociological Abstracts searched 1963 to May 2005

. Criminal Justice Abstracts searched 1968 to March 2005

-Criminal Justice Periodical Index searched 1981 to June 2005

-National Criminal Justice Reference Service (NCJRS) searched early 1970 s to June 2005

- Child Abuse and Neglect Abstracts (National Child Abuse and Neglect or NCCAN Clearinghouse) searched to June 2005

- Legal Resource Index searched 1977 to June 2005

-Dissertation Abstracts International searched late 1960s to 2005

-PsycINFO searched 1872 to May 2005

-ERIC searched 1966 toNovember 2004

.Social Sciences Citation Index searched 1956 to June 2005

-Bibliography of Nordic Criminology searched 1945 to June 2005

The following strategy was used to search MEDLINE. The terms were modified where necessary to meet the requirements of the other databases listed above.

MEDLINE searched 1966 to May 2005 through OVID

\section{Adolescent/ OR}

(young person or young people).tw. OR

(youth\$ or juvenile\$ or adolescen\$ or teenage\$).tw

AND

Juvenile Delinquency/OR

exp Crime/ OR

exp Violence/ OR

(offender\$ or delinquen\$ or trouble\$ or violen\$ or crime or crimi-

nal\$ or aggress\$).tw. OR

Conduct Disorder/ OR

(antisocial adj3 behavio\#r\$).tw. OR

(behavio\#r adj3 disorder\$).tw. OR

(conduct adj3 disorder\$).tw.

AND

Cognitive Therapy/ OR

cognitive.tw. OR

CBT.tw. OR

social skill\$ train $\$$.tw. OR

aggression replacement train $\$$.tw. OR

moral reason\$.tw. OR

moral reconation terap\$.tw. OR

MRT.tw. OR moral discussion group\$.tw. OR

MDG.tw. OR

equip.tw.

AND

institution\$.tw. OR

residential.tw. OR

Prisons/OR

(prison or prisons).tw. OR

(correction\$ adj3 program\$).tw. OR

(correction\$ adj3 facilit\$).tw. OR

out of home treatment\$.tw. OR

rehabilitat\$.tw. OR

group treatment\$.tw. OR

incarcerate\$

Trials filters were not used, because it would limit the searches in the listed social and welfare databases.

\section{Data collection and analysis}

Details of methods described in the protocol, which were not necessary in this version of the review, appear in Table 1.

\section{Selection of studies}

Selection of primary studies was based on the inclusion criteria described above. Complete copies of all titles and abstracts considered eligible by at least one of the reviewers (TA, BA) were imported into an Access database and full text copies were obtained. The retrieved full text was then independently read by two reviewers (TA, BA) for eligibility. No disagreements occured.

\section{Data extraction and management}

Data were extracted independently by two reviewers (BA and TA). Any disagreements were discussed and the authors of studies were contacted to assist in resolving problems.

\section{Assessment of risk of bias in included studies}

\section{Quality assessment}

Details of each included study were coded into a database in Access. Two reviewers (TA and $B A$ ) performed the coding independently of each other. One reviewer (BA) assigned each eligible study to quality categories as described below.

\section{Prevention of selection and Allocation Bias}

MET = Resulting sequences are unpredictable (explicitly stated use of either computer-generated random numbers, table of random numbers, drawing lots or envelopes, coin tossing, shuffling cards, or throwing dice). UNCLEAR = statement that the study was randomised but no description of the generation of the allocation sequence or statement(s) indicating that random allocation was used in some but not all cases. NOT MET = No attempt to prevent selection bias or clearly non-randomised allocation sequence.

For Non-RCT studies an assessment of initial equivalence between intervention and control groups is made on the basis of demographics, risk factors, test performance or other pre-intervention data available.

\section{Concealment of allocation sequence}

MET = Neither participants nor investigators can foresee assignment (e.g. central randomisation performed at a site remote from 
trial location; or use of sequentially numbered, sealed, opaque envelopes). UNCLEAR = statement that the study was randomised but not describing the concealment of allocation. NOT MET = No attempt to conceal allocation sequence.

\section{Prevention of Performance Bias}

MET = Interventions other than CBT avoided, controlled or used similarly across comparison groups. UNCLEAR = Use of interventions other than CBT not reported and cannot be verified by contacting the investigators. NOT MET = Dissimilar use of interventions other than CBT across comparison groups, i.e. differences in the care provided to the participants in the comparison groups other than the intervention under investigation.

\section{Prevention of Detection Bias}

$M E T=$ Assessor unaware of the assigned treatment when collecting outcome measures UNCLEAR = "Blinding" of assessor not reported and cannot be verified by contacting investigators. NOT MET = Assessor aware of the assigned treatment when collecting outcome measures.

\section{Prevention of Attrition Bias}

MET = Losses to follow up less than $20 \%$ and relatively equally distributed between comparison groups (e.g. $18 \%$ and $20 \%$ ). UNCLEAR $=$ Losses to follow up not reported. NOT MET $=$ Losses to follow up $20 \%$ or greater, or not equally distributed between comparison groups (e.g. 18\% and 24\%). Percentages above were set in the protocol.

\section{Intention-to-treat}

MET = Intention to treat analysis performed or possible with data provided. UNCLEAR = Intention to treat not reported, and cannot be verified by contacting the investigators. NOT MET = Intention to treat analyses not done and not possible for reviewers to calculate independently.

\section{Measures of treatment effect}

\section{Binary data}

For binary outcomes, for example, 'offence' or 'no offence', a standard estimation of the Odds Ratio with the $95 \%$ confidence interval was calculated. Risks, risk ratios and NNT were also calculated. All analyses are explained, since many practitioners are unfamiliar with the various ways of computing binary outcome results.

See also Table 1

\section{Dealing with missing data}

Missing data and dropouts were reported for each included study and the review reports the number of participants who are included in the final analysis as a portion of all participants in each study. When possible, intention-to-treat analyses were performed and the influence of missing data on the results were analyzed and discussed.

\section{Assessment of heterogeneity}

Assessment of heterogeneity was made visually and by examining $I^{2}$ (Higgins 2002). If there was significant heterogeneity among primary outcome studies, according to a Chi ${ }^{2}$ test $(p<.05)$ and after an examination of $\mathrm{I}^{2}$, the following factors were considered as possible explanations: design quality and publication bias. Review Manager was used to assess the impact of heterogeneity.

\section{Assessment of reporting biases}

Funnel plots were drawn to investigate any relationships between effect size and study precision in terms of sample size. Although larger studies in general showed smaller effect sizes, the relationship was usually not significant at the $95 \%$ level of significance.

\section{Data synthesis}

\section{Meta-analysis}

Data were analysed using both fixed effect and random effects models, although a random effects model was more appropriate due to heterogeneity across studies.

\section{Subgroup analysis and investigation of heterogeneity}

See Table 1.

\section{Sensitivity analysis}

Primary analyses were based on available data from all included studies relevant to the comparison and outcome of interest. In order to assess the robustness of conclusions to quality of data and approaches to analysis, sensitivity analyses were performed. These included:

a) Study design. RCTs and Non-RCTs were analyzed separately but the impact of the study design on the overall results was also assessed.

b) Intention to treat. For dichotomous outcomes, such as 'offended' or 'not offended', the authors assumed that those who were lost to follow up (i) had proportionately the same outcomes as those who completed in the control group (ii) experienced the successful outcome (iii) experienced the unsuccessful outcome.

c) Drop-out. Studies with large or severe imbalance in terms of numbers of attrition were excluded from the analysis to assess their influence on the overall result.

\section{RE S U L T S}

\section{Description of studies}

\section{Results of the search}

A total of 94 studies were identified in the searches and after reading the title and abstract, 35 full-text copies were retrieved.

\section{Included studies}

Thirteen papers were initially judged to meet the inclusion criteria for this review. Later it appeared that data from one included study (Drake 2005) were published in two separate reports (see references and Table of Characteristics of Included Studies). This assessment procedure therefore resulted in twelve studies for the present analyses.

\section{Study methods}

There were five studies with random allocation (RCT) to CBT treatment and comparison conditions (Armstrong 2003; Greenwood 1993; Leeman 1993; Shivrattan 1988; Guerra 1990) and seven with Non-RCT designs (Drake 2005; Bottcher 1985; Cann 2003; Deschamps 1998; Farrington 2002; Sarason 1973; Robinson 1994). Two studies started out as RCT studies but failed to allocate partic- 
ipants randomly and ended up as a Non-RCTs (Sarason 1973; Farrington 2002). In the study by Armstrong 2003 the randomization procedure was not implemented as planned but the results are presented in a manner which makes it possible to treat the failures of randomization as drop-outs (see Characteristics of included studies for details).

\section{Setting of studies}

The twelve studies included within this review were undertaken between 1973 and 2005 in three countries. Eight studies were conducted in the USA (Armstrong 2003; Drake 2005; Bottcher 1985; Greenwood 1993; Guerra 1990; Leeman 1993; Sarason 1973; Robinson 1994), two in Canada (Deschamps 1998; Shivrattan 1988) and two in the UK (Cann 2003; Farrington 2002). Most of the studies were conducted in only one site and the only study that draws on data from many sites (Cann 2003) does not report the number of sites or specific results from each site.

\section{Sample characteristics}

One study included girls only (Bottcher 1985), three included both boys and girls (Drake 2005; Guerra 1990; Robinson 1994) and 8 included only boys (Armstrong 2003; Cann 2003; Deschamps 1998; Farrington 2002; Greenwood 1993; Leeman 1993; Shivrattan 1988; Sarason 1973). The age at the time of incarceration varied between 12 and 21 with an average generally around 15-16. Results were never reported separately for boys and girls or for different age groups, which made such analyses impossible. One study (Drake 2005) focused on juvenile offenders with mental health problems.

\section{Intervention characteristics}

There was a variety of cognitive behavioural treatments used in the included studies. Two used Reasoning and Rehabilitation (Cann 2003; Robinson 1994) or Enhanced Thinking Skills (Cann 2003), two used Moral Reconation Therapy (Armstrong 2003; Deschamps 1998), one used Dialectical Behaviour Therapy (Drake 2005), two were focused on what might be called Social Interactional Training (Shivrattan 1988) or social Modelling (Sarason 1973) and three were more comprehensive programs. One of the comprehensive programs includes Positive Peer Culture plus Reality Therapy plus Criminal Thinking Errors (Greenwood 1993) and another, called EQUIP (Leeman 1993), is a combination of Positive Peer Culture and ART, while the third more comprehensive program was a military camp program which comprises Social Skills Training, Vocational Training, Challenging justifications for crime and Work Training (Farrington 2002). Two interventions focused on thinking, Cognitive Mediation Training (Guerra 1990) and Situational Decision Making (Bottcher 1985), although all interventions included both a cognitive and a behavioural aspect. Although hard to estimate, the total time of the intervention varied from around 20 hours to daily activities for a year (See Characteristics of Included Studies). The intervention in four studies (Drake 2005; Bottcher 1985; Guerra 1990; Shivrattan 1988) was directed at interpersonal or cognitive skills in general, but applied and practised in a criminal setting. Thus, all studies included criminogenic needs to some extent.

\section{Comparison conditions}

In seven studies (Armstrong 2003; Drake 2005; Cann 2003; Deschamps 1998; Farrington 2002; Leeman 1993; Robinson 1994) the standard treatment was regular prison activity. In four studies (Greenwood 1993; Guerra 1990; Sarason 1973; Shivrattan 1988) it was a training school of some kind and in one study it was unclear whether it was a prison or a school (Bottcher 1985). Three studies with Non-RCT designs used historical controls drawn from young people who had been at the same institution before introduction of the CBT-program (Drake 2005; Bottcher 1985; Robinson 1994). The other comparisons were drawn from other institutions (Cann 2003; Deschamps 1998; Farrington 2002; Greenwood 1993) or from the same institution (Armstrong 2003; Guerra 1990; Leeman 1993; Sarason 1973; Shivrattan 1988). In addition to a standard treatment control condition, four studies used a second comparison group. One study (Leeman 1993) used a second control group which initially received a five-minute motivational instruction. The recidivism data for the two control groups were however pooled by the author. Three studies used a comparison group which received an active treatment other than CBT, i.e. an alternative treatment comparison group. One of them (Guerra 1990) used an alternative treatment comparison group which received Attention Control in a 'dose' similar to the intervention group. The study by Shivrattan 1988 used an alternative treatment comparison group which received Stress Management Training and Sarason 1973 used a Discussion Group without any behavioural training as an alternative treatment comparison group. Thus, three studies used an alternative to CBT as an active treatment in addition to some kind of control condition.

\section{Outcome measures}

Recidivism was always reported in terms of official records, but some studies also provided data regarding transfer to adult correctional institution or escape from the institution (Deschamps 1998) or self-reported criminal activity (Bottcher 1985; Greenwood 1993; Guerra 1990; Leeman 1993). Some studies (Sarason 1973; Leeman 1993; Shivrattan 1988; Guerra 1990; Robinson 1994) included psychological or other behavioural outcomes (drug use, social cognition, social skills, moral development, self-description, self-concept, goal scale, activity preference questionnaire, internalization-externalization, MMPI, Jesness Behaviour checklist: Observer and Self Appraisal forms, Watson-Glaser Critical Thinking Appraisal, California Psychological Inventory, Raven's Progressive Matrices), but none of the psychological or behavioural outcomes was used in more than one study and usually not measured at follow-up assessments.

\section{Duration of follow-up observations}

The time since release from the institution varied from 6 months (Leeman 1993; Armstrong 2003; Greenwood 1993; Robinson 1994) to 12 months (Armstrong 2003; Greenwood 1993; Guerra 1990; Leeman 1993; Shivrattan 1988; Drake 2005; Bottcher 1985; Cann 2003; Deschamps 1998; Farrington 2002) to around two years (Armstrong 2003; Cann 2003; Farrington 2002; Guerra 1990; Sarason 1973). In summary, four studies provided data at 6 months while ten studies provided follow-up data on recidivism of one year or more, and five studies provided follow-up data at 24 months.

\section{Independence - allegiance}

Five studies were conducted by independent authorities (Armstrong 2003; Drake 2005; Cann 2003; Farrington 2002; Greenwood 1993) and three authors had no obvious relationship to those responsible for the intervention (Bottcher 1985; Deschamps 1998; Robinson 1994). However, five authors seem to have been relatively closely involved in the intervention (Guerra 1990; Leeman 1993; Sarason 1973; Shivrattan 1988). 


\section{Excluded studies}

Twenty-two studies were excluded because they did not include adolescents or did not report recidivism (see Table of Excluded Studies).

\section{Risk of bias in included studies}

\section{Allocation}

Concealment of the allocation sequence is only possible in the RCT studies and was not reported in any study. The method of randomization was not specified in any study, but except for the study by Greenwood 1993, randomization seems to have taken place at the institution where a specified number of participants were randomized to each condition.

\section{Blinding}

In all studies it is clear that youth and therapists or teachers in the CBT interventions were aware of the allocation and participants in the comparison conditions might have been aware of the allocation if their active participation was required (e.g. to fill in questionnaires or tests). In some of the Non-RCT studies only archival data were used and such data are usually collected long after the youth has left the institution, which means that they were probably not aware that they participated in a study. With respect to blinding of assessment, recidivism data were usually collected more than a year after the youth had left the institution and such archival data may be considered blind; however, law enforcement officials might have known that a youth was receiving CBT and this might have influenced key decisions about youth (e.g. arrests, convictions and incarceration).

\section{Incomplete outcome data}

Robinson 1994 reported results only for participants who attended $90 \%$ of the sessions and passed the curriculum and Guerra 1990 initially randomized 165 youth to three conditions, but reported outcomes for only 120 of the 126 who completed the program and the post-test. It was possible to obtain recidivism data for 81 of the 120 , which means that the results are based on less than $50 \%$ of those initially randomized. This makes an ITT analysis impossible for these two studies. In the other ten studies information on the total number of participants was provided and three studies (Cann 2003; Farrington 2002; Greenwood 1993) provided information both on the total number of participants treated as well as those who completed the program. Since intent-to-treat analyses were possible to perform for 10 of the 12 studies no separate analyses for those who completed the program were made (See Additional tables: Table 10: Frequencies and Table 11: Frequencies Alternative treatments). Special care should be taken when interpreting results including the studies by Robinson 1994 and Guerra 1990, however.

\section{Other potential sources of bias}

\section{Assessment of initial differences between groups}

One of the RCTs did not report the results of an analysis of the initial equivalence between the treatment and comparison groups (Shivrattan 1988). Three of the RCT-studies (Armstrong 2003; Greenwood 1993; Leeman 1993) assessed equivalence on criminal risk factors and demographic variables, while Guerra 1990 assessed equivalence on psychosocial variables such as social cognition and behavior ratings. One of the Non-RCT studies did not re- port any data on the equivalence initially (Deschamps 1998), but five (Bottcher 1985; Cann 2003; Drake 2005; Robinson 1994; Sarason 1973) Non-RCTs found equivalence on criminal risk factors and demographic variables. Farrington 2002 compared the groups both with respect to predicted and actual reconviction rates as estimated by an OGRS algorithm developed in the UK. The comparison group had a higher predicted as well as actual risk and the groups were not equivalent initially.

Although pre-test scores in some studies were used as covariates in the analyses of outcome variables other than recidivism no such adjustments were made for recidivism except for the study by Drake 2005.

In summary, the comparability of the treatment and control groups initially varies among the studies. Equivalence on specific variables seems to be ascertained in 9 studies (Armstrong 2003; Drake 2005; Bottcher 1985; Cann 2003; Greenwood 1993; Guerra 1990; Leeman 1993; Robinson 1994; Sarason 1973), while non-equivalence was found in one study (Farrington 2002). Shivrattan 1988 did not report the results of pre-test analyses and Deschamps 1998 did not report any information concerning initial equivalence of the groups.

\section{Standardization of outcome assessments}

Archival data on arrests and convictions are routinely collected, though follow-up periods varied both between and within studies. All follow-ups were, however, defined as time elapsed since release from the institution. Some studies used a fixed time after release (e.g. 12 months) while others used a minimum and maximum time (e.g. 18-34 months) elapsed since release or admission. The small differences in follow-up intervals were organized to 6, 12 and 24 months on the average. A number of studies (Bottcher 1985, Greenwood 1993, Guerra 1990, Leeman 1993, Robinson 1994, Sarason 1973, Shivrattan 1988) used additional outcomes, but it was not possible to organize them into conceptually homogenous groups in order to perform a meta-analysis.

\section{Quality assessment}

An assessment of the quality of the included studies based on the criteria stated above is provided by the Additional tables: Table 9. The quality of the study by Guerra 1990 is low because the attrition is very large and no ITT analysis is possible. The second study that suffers from a bias is the study by Farrington 2002, where the groups are clearly not comparable from the beginning, although the study is well done in other respects. The bias is in favour of the intervention and there is no way of controlling for it, which requires attention while interpreting the results. The study by Armstrong 2003 also has some attrition due to the problems of implementing the randomization, but this is accounted for and cannot be considered to be a serious bias. Finally, some caution is required while interpreting results including the study by Robinson 1994 since the results do not reflect ITT. In all, there are three studies that require special attention in the analyses due to methodological biases (Guerra 1990; Farrington 2002 and Robinson 1994).

\section{Effects of interventions}

All analyses were conducted within RevMan4.2.3 using odds ratios (OR) with a 95\% confidence interval $(\mathrm{Cl})$. The results are organized so that first the RCTs and the non-RCTs are analyzed separately and then together in order to see the total effects. 
The first analysis was conducted using the raw frequencies of the six-month follow-up period (Analysis 1.1). The next analyses were conducted using data from one year follow-up, and the impact of drop-outs is also analysed (Analysis 2.1, Analysis 2.2, Analysis 2.3). The observed heterogeneity is analysed by means of a funnel plot (Figure 1) and by sensitivity analyses excluding the two studies with lower quality (Analysis 2.4 and Analysis 2.5 ).

\section{Figure 1. Fig 1: Funnel plot. Funnel plot with $95 \%$ confidence interval}

\section{Review: Cognitive-behavioral treatment for antisocial behavior in youth in residential treatment (Version 14) \\ Comparison: $0112 \mathrm{~m} \mathrm{~T}$ vs C \\ Outcome: $\quad 01$ Table 1: $12 \mathrm{~m}$ Droupouts=Proportional}

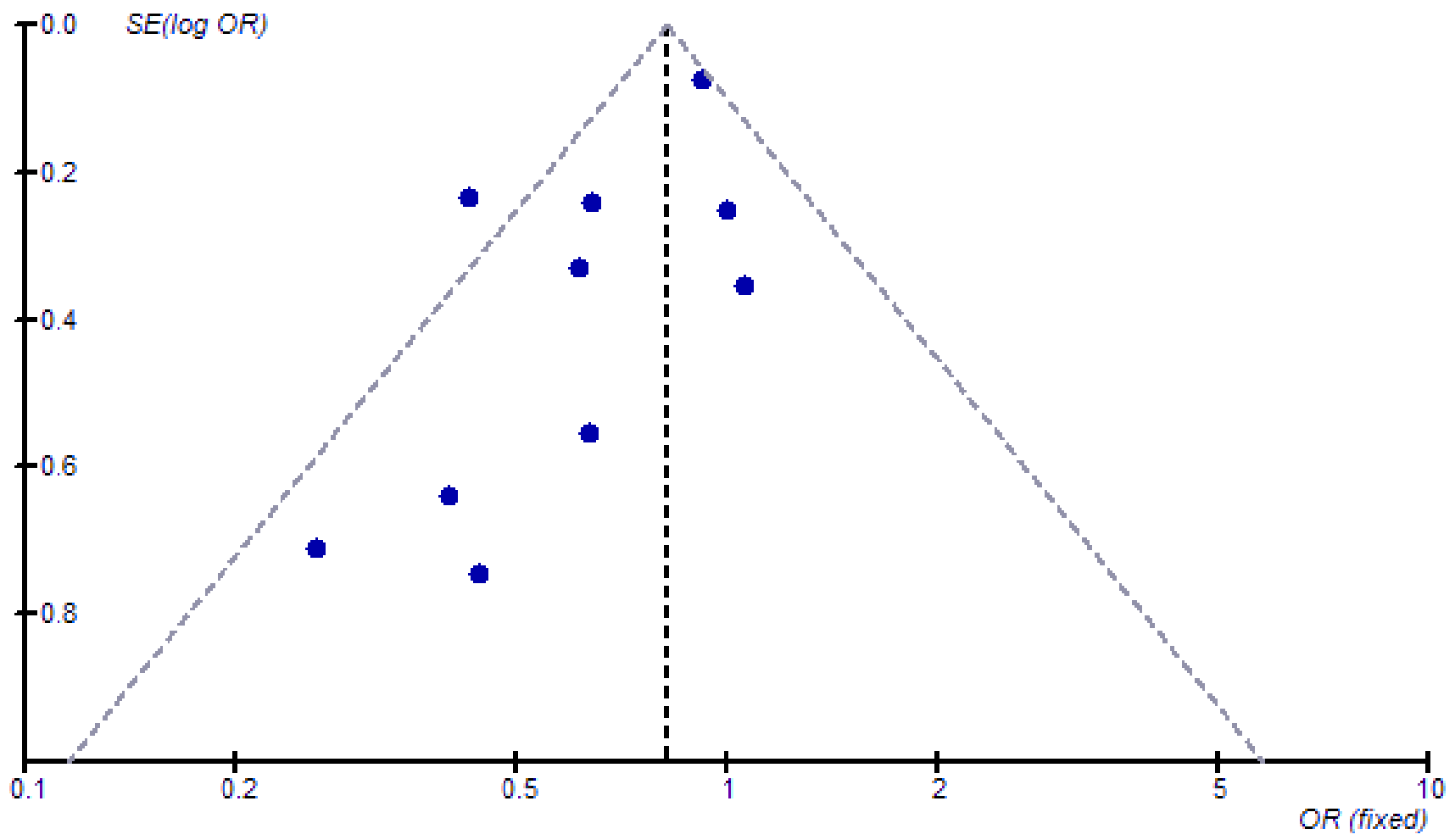

Next, the recidivism data for 24 months follow-up are analyzed (Analysis 3.1); finally, CBT versus alternative treatments are analyzed (Comparison 04).

In addition to the statistical analyses, Table 2 includes information on quality assessment for included studies and Table 3 and Table 4 report the raw frequencies on which theanalyses rely. Table 5 provides some baseline information about the participants in the studies.

\section{Recidivism at 6 months: CBT vs. Control (Analysis 1.1)}

Recidivism data is available for three RCTs and one non-RCT at six months follow-up and the results show a very small and non-significant effect in favour of CBT. The results have to be interpreted by caution for a number of reasons. First, the power to detect a difference of a few percent in recidivism as significant is very low due to the small number of studies and participants (about 280 in each group), second the data is not adjusted to reflect intention-to-treat but are the raw frequencies reported in the papers, third the results for the treatment group in Robinson 1994 are based on those who completed treatment successfully. The results show no significant effects for any single study, for the RCTs, the Non-RCT or the Total effect and there is no indication of heterogeneity.

Recidivism at 12 months follow-up: CBT vs. Control ( Analysis 2.1; Analysis 2.2; Analysis 2.3; Analysis 2.4; Analysis 2.5;)

At 12 months there are more than 1900 participants in both the CBT and comparison groups, which means that there is $80 \%$ chance or power to detect a systematic difference of a few percent as significant. In line with the protocol and in order to assess the impact of attrition we analyzed the recidivism data at 12 months in three different ways. First it was assumed that the proportion of recidivists was the same among the drop-outs as in the sample studied. At 12 months the random effects model odds ratio for the five RCTs is: $\mathrm{OR}=0.71 \mathrm{Cl}: 0.48-1.04$; For the Non-RCTs OR $=0.69 \mathrm{Cl}: 0.47-1.01$; None of the subtotals is significant, however the OR for the Total is significant in favour of CBT: OR $=0.69 \mathrm{Cl}$ : $0.53-0.90$ but with significant heterogeneity (Chi2 $=17.59, \mathrm{df}=9, \mathrm{p}=0.04,12=48.8 \%$ ), which means that a fixed model is not supported by the data. The ORs are virtually identical in the RCT and Non-RCT groups.

In the second analysis it was assumed that none of the drop-outs were recidivists and in the third analysis it was assumed that all 
drop-outs were recidivists. Since Guerra 1990 and Armstrong 2003 were the only studies with a substantial attrition, it is obvious the handling of drop-outs only has a marginal effect on the outcome. The results are almost identical and it does not really matter if the drop-outs are treated as failures or successes or treated in proportion to the actual frequencies. Therefore, all further analyses will be made with drop-outs treated proportionally, and interpreted to reflect intention-to-treat, bearing in mind that the study by Guerra is an exception (Guerra 1990).

\section{Sensitivity analyses}

In order to further explore the heterogeneity a funnel plot relating the standard error to OR of each study was drawn (Figure 1). The lack of points at the lower right corner suggests that there might be a publication bias present and the study (Farrington 2002) outside the line of the $95 \%$ confidence interval on the left side has an unexpectedly high OR in relation to the standard error. This study had a significant pre-treatment difference in favour of the treatment which suggests that the odds ratio might be biased. A sensitivity analysis excluding Farrington 2002 is shown, where the heterogeneities both among the Non-RCT studies and the Total are reduced to a non-significant level. In this analysis the confidence intervals of the RCTs and Non-RCTs still overlap suggesting that the somewhat lower odds ratio for the RCTs (OR $=0.71 \mathrm{Cl}: 0.48-1.04)$ than the Non-RCTs (OR=0.85 Cl: $0.67-1.07$ ) is not significant. Although none of the two subtotals is significant, the Total is significant $(\mathrm{OR}=0.81 \mathrm{Cl}: 0.67-0.98)$.

The second study requiring attention due to somewhat lower quality, in this case due to attrition and no ITT-results, is the study by Guerra 1990. A second sensitivity analysis was performed with these two studies excluded. The results for the random effects model are very similar to those found when only Farrington 2002 was excluded. $\mathrm{RCTs}$ give a little lower odds ratio $(\mathrm{OR}=0.67 \mathrm{Cl}: 0.41$ - 0.1.11) than the Non-RCTs (OR=0.85 Cl: 0.67-1.07). The ORs are however virtually the same as in the previous analysis.

In summary, the results for 12 months suggest that there is a significant effect in favour of CBT and this effect is not due to the inclusion of two studies with somewhat lower quality or to the handling of attrition. Farrington's study seems to represent an overestimation of the effects of CBT and contributes to the relatively favourable result for the Non-RCTs. With that study excluded, the RCTs give a somewhat more favourable result for CBT than the Non-RCTs, although the difference is very small.

Recidivism at 24 months follow-up: CBT vs. Control (Analysis 3.1) The recidivism rate at 24 months includes five studies which also were included in the analysis of 12 month data (Armstrong 2003; Cann 2003; Drake 2005; Farrington 2002; Guerra 1990) and one study (Sarason 1973) which only reported data from at least 18 months post admission. The data do not come from independent sources since the same participants were also analyzed at 12 months follow-up in five of the included studies. Neither the Total odds ratio $(\mathrm{OR}=0.83 \mathrm{Cl}: 0.68-1.02)$, nor the Non-RCT odds ratio $(\mathrm{OR}=0.74 \mathrm{Cl}: 0.53-1.04)$ or the two RCTs (OR $=92 \mathrm{Cl}: 0.59-1.43)$ are significant. Although the Total OR is almost identical to that of 12 months, this result has to be interpreted with caution since two of the six studies have lower methodological quality as described under Quality assessment.

Recidivism at 12 and 24 months: CBT vs. Alternative treatment ( Analysis 4.1)
The comparisons between CBT and alternative treatments are made a little different from the previous analyses. Since there are so few studies, and previous analyses have shown very small differences between RCTs and Non-RCTs, the analyses are made separately for 12 months and 24 months, irrespective of the type of study. The comparison of CBT with an alternative treatment is shown. The study by Guerra 1990 is included at both follow-ups and does not provide independent data which is a small but important bias since the CBT participants in the Guerra 1990 study are used for both follow-up occasions. There are no significant differences between CBT and the alternative treatments at any follow-up period. This analysis has to be interpreted with caution since the total number of participants is very small, partly confounded and one of the studies has a lower methodological quality. However, excluding Guerra 1990 does not give any other result.

\section{Other expressions of effect}

In addition to the odds ratio, it is useful to look at the risk of recidivism within 12 months for participants treated with and without CBT in residential treatment as well as the Relative Risk (RR), the Risk Difference (RD) and the Number Needed to Treat (NNT). The RR for recidivism is 0.85 for both RCT and Non-RCTs, which means that the risk for recidivism within 12 months for those treated with CBT while in residential treatment is around $85 \%$ of the risk for those treated with regular treatments. The average risk for CBT recidivism is $43 \%$ with a variation between $15 \%$ and $80 \%$ in individual studies while the average risk for recidivism in the Control conditions is $53 \%$ with a variation between $25 \%$ and $89 \%$ in individual studies. The absolute difference in recidivism between the CBT treatments and the Controls is thus $10 \%$, however when weighted by the number of participants in each study, the weighted $\mathrm{RD}$ is $9 \%$. Thus the risk for recidivism within 12 months after release is reduced by about $10 \%$ if a young adolescent is treated with CBT rather than standard treatment while in residential treatment. Based on the absolute risk reduction, the number needed to treat (NNT) is 10 (Higgins 2005), which means that one will have to treat ten young adolescents to produce one more who does not reoffend compared to a Control condition. Thus, one more out of every ten (NNT) will be successfully treated with CBT in residential treatment than in standard treatment.

\section{DISCUSSION}

The results suggest that $\mathrm{CBT}$ is significantly better than the control conditions at 12 months follow up, but not at 6 or 24 months. Does this mean that the effects take some time to appear and last for only one year? An alternative explanation is that the effects are similar at all follow-up intervals, but the present review does not have enough statistical power to detect the effects due to too few participants and studies at 6 and 12 months. There is some support for this alternative explanation in the fact that the results at 24 months clearly favor CBT and one (Sarason 1973) of the six studies found a significant effect after 24 months. Six months might be a too short period for any differences in recidivism to show up.

The power explanation is highly relevant also for understanding the results at 12 months follow-up. There is one very large study, Cann 2003, with more than 1500 young men treated by two variants of CBT, Enhanced Thinking Skills and Reasoning and Rehabilitation, who are compared to young men who were treated before CBT was introduced in the English prison system. The authors found a small, and not significant, difference in recidivism in favour of CBT in an 
ITT analysis at twelve months follow-up. At 24 months there were no differences. In fact, at twelve months only one single (biased) study (Farrington 2002) found a significant difference, while 7 of the other studies found tendencies in the same direction and the remaining two found no differences in recidivism at all. However, after pooling the results from all 10 studies at 12 months it became evident that there is a significant, but relatively small effect of CBT vs. standard treatment. The reason for this apparent inconsistency is that all but one study (Cann 2003) had too few participants to detect a small positive effect of CBT, but pooling all ten studies to an analysis based on more than 1900 participants was enough to detect it. The odds ratio for the random effects model is 0.69 , which corresponds to standardized mean difference (d) effect size, (ES) of approximately 0.25 , which is usually considered to be a small effect. The risk of recidivism is reduced by $10 \%$ on the average and you can expect one less recidivist for every ten youth treated by standard methods. The possibility of detecting such a small effect as a significant difference in a single study is very limited (Drake 2005). Our results compare well with the review by Genovés 2006 who found the treatment groups to be around $8 \%$ lower in recidivism than the control groups (Genovés 2006).

A variety of $C B T$ interventions were used by the included studies and the only interventions used by more than one study were Moral Reconation Therapy, which was used in the studies by Armstrong 2003 and Deschamps 1998 and Reasoning and Rehabilitation, which was used in the studies by Cann 2003 and Robinson 1994. The results for these studies are no different than the general results, which makes it impossible to discern any particularly promising individual intervention within the broad concept of CBT. Although no regression analyses were undertaken in the present review, the notable variation in duration and intensity of the CBT intervention does not seem to be systematically related to the size of the effect.

Three studies compared CBT to an alternative active treatment and no significant differences between the alternative treatments and CBT were found, which suggests that not only CBT, but other kinds of treatment might produce similar results. Unfortunately, there are too few alternative treatments to allow conclusions regarding the effectiveness of any specific alternative to CBT. The comparisons used were Attention control, Stress management and Discussion group and all participants received the same exposure as those in the CBT condition. All three were controls for the behavioural part of the CBT and the first two had no focus on criminogenic needs. Again, the number of studies is too small to warrant any conclusions other than that there is no support for the conclusion that $\mathrm{CBT}$ is the only effective treatment.

There was no difference in effect between RCTs and Non-RCTs and the methodological quality was essentially the same for the RCTs and the Non-RCTs, which is mainly due to the fact that most of the studies used archival data which allowed for control initial inequalities and attrition and made ITT analyses possible. The sensitivity analyses showed that the impact of the few methodological flaws was very limited or non-existent. The sources of heterogeneity cannot be investigated thoroughly in the present study and therefore, currently, a random effects model seems more adequate than a fixed effects model.

A limitation to keep in mind while drawing conclusions from the present meta-analysis is that the results may be influenced by a selection bias. There are only five RCT studies which allow for bet- ter control of selection biases than the seven Non-RCT studies. Although the initial equality of the treatment and comparison groups were assessed also in most of the Non-RCTs, there is always the possibility that the assessments were made on variables that do not reflect aspects of importance for outcome. This is especially true when the comparison groups are drawn from historical groups or other sites which introduces other differences between the treatment and comparison group than the delivery of the CBT treatment. The fact that almost all studies used some form of criminal variables for assessment of initial equality is good, however, since previous criminal behavior is a strong predictor of recidivism.

Another possible weakness of the present study is that the funnel plot indicates a possibility for a publication bias (Figure 1). If it is true that there is a small random and positive effect of CBT compared to standard treatment there should be at least a few small studies which show zero or negative results. The absence of such studies may have many explanations, but the possibility remains that the present effects represent an overestimation due to a lack of small studies with less positive results.

\section{AUTHORS' CONCLUSIONS}

\section{Implications for practice}

There is relatively strong support for a small effect of CBT in residential treatment one year after release. A variety of $C B T$ interventions seem to be effective and although many studies investigated have used more comprehensive programs, there are also individual studies who implement only one particular CBT intervention. There is not enough information to suggest what intensity or time frame for treatment that is more effective. The interventions range from a few hours up to a year. These results are somewhat in contrast to the current practice in the Nordic countries at least, where the most widely used approach is some form of milieu-therapy (Sallnäs 2000), although CBT seems to become more and more in focus (Gundersen 2005). Internationally, the most widely used approach to treatment in criminal justice today seems to be variations of Cognitive Behavioral Therapy (Little 2005).

The evidence does not support the necessity to focus on criminogenic needs or that CBT is the only effective treatment. Alternative treatments outside the CBT domain may also prove to be effective.

\section{Implications for research}

The use of archival data may provide researchers with the possibility of performing intention-to-treat analyses with relatively large samples where initial differences between comparison groups may be handled in a satisfactory manner. This possibility should be considered when the problems of implementing a more controlled RCT study are overwhelming. The attrition may ruin the intention to control for selection biases by means or random assignment. The needs for future research are somewhat contradictory. On the one hand, there is a need for more relatively small studies comparing CBT to Control conditions in order to fill the publication gap. On the other hand, the expected effects of the intervention are relatively small, which calls for a relatively large study in order to reach significance. One way out of this dilemma might be to rely more on effect size measures than on tests of significance for future research in this field 


\section{ACK N OWLEDGEMENTS}

The authors wish to thank The Nordic Campbell Centre for financial and educational support. Many thanks to the work by Terje Ogden and Tine Egelund for their work on the protocol and draft review prior to September, 2006.
Thanks also to Geraldine Macdonald, Jane Dennis and Joanne Abbott at the Cochrane Developmental, Psychosocial and Learning Problems Group for editorial and administrative support. Special thanks to Mark Lipsey for providing access to studies and to Jeff Valentine for comments on an earlier version of the review. 
REFE RE N CES

\section{References to studies included in this review}

Armstrong 2003 \{published data only\}

Armstrong TA. The effect of moral reconation therapy on the recidivism of youthful offenses. Criminal Justice and Behavior 2003;30(6):668-87.

\section{Bottcher 1985 \{published data only\}}

Bottcher J. The Athena Program. An evaluation of a Gils' treatment program at the Fresno County Probation Department's Juvenile Hall. Sacramento CA: California Department of the Youth Authority, 1985.

\section{Cann 2003 \{published data only\}}

Cann J, Falshaw L, Nugent F, Friendship C. Understanding what works: accredited cognitive skills programmes for adult men and young offenders: Research Finding 226. London UK: Home Office, 2003.

\section{Deschamps 1998 \{published data only\}}

Deschamps T. MRT: is it effective in decreasing recidivism rates with young offenders? (Masters' thesis). Ontario, CA: University of Windsor, 1998.

\section{Drake 2005 \{published data only\}}

Barnowski R. Preliminary Findings for the Juvenile Rehabilitation Administration's Dialectic Behavior Therapy Program. Olympia, WA: Washington State Institute for Public Policy, 2002.

* Drake E, Barnoski R. Recidivism findings for the Juvenile Rehabilitation Administration's dialectical behaviour therapy program: Final report. Vol. Document No. 06-05-1202, Olympia, WA: Washington State Institute for Public Policy, 2005.

\section{Farrington 2002 \{published data only\}}

Farrington D, Ditchfield J, Hancock G, Howard P, Jolliffe D, Livingston $\mathrm{M}$, et al. Evaluation of two intensive regimes for young offenders: Home Office Research Study 239. London, UK: Home Office, 2002.

\section{Greenwood 1993 \{published data only\}}

Greenwood PW, Turner S. Evaluation of the Paint Creek Youth Center: A residential program for serious delinquents. Criminology 1993;31(2):263-79.

\section{Guerra 1990 \{published data only\}}

Guerra NG, Slaby RG. Cognitive mediators of aggression in adolescent offenders: 2 . Intervention. Developmental Psychology 1990;26:269-77.

\section{Leeman 1993 \{published data only\}}

Leeman LW, Gibbs J, Fuller D. Evaluation of a multi-component group treatment program for juvenile delinquents. Aggressive Behavior 1993;19:281-92.
Robinson 1994 \{published data only\}

Robinson SC. Implementation of the cognitive model of offender rehabilitation and delinquency prevention ( $\mathrm{PhD}$ Dissertation). Salt Lake City, UT: University of Utah, 1994.

\section{Sarason 1973 \{published data only\}}

Sarason IG, Ganzer VJ. Modeling and group discussion in the rehabilitation of juvenile delinquents. Journal of Counseling Psychology 1973;20(5):442-49.

Shivrattan 1988 \{published data only\}

Shivrattan JL. Social interactional training and incarcerated juvenile delinquents. Canadian Journal of Criminology 1988;30:145-63.

\section{References to studies excluded from this review}

Arnold 2003 \{published data only\}

Arnold EM, Kirk RS, Roberts AC, Griffith DP, Meadows K, Julian J. Treatment of incarcerated, sexually-abused adolescent females: an outcome study. Journal of Child Sexual Abuse 2003;12(1):123-39.

Bailey 2004 \{published data only\}

Bailey KA, Baker AL, Webster R, Lewin T. Pilot randomized controlled trial of a brief alcohol intervention group for adolescents. Drug and Alcohol Review 2004;23(2):157-66.

\section{Escamilla 1998 \{published data only\}}

Escamilla AG. A Cognitive Approach to Anger Management Treatment for Juvenile Offenders. Journal of Offender Rehabilitation 1998;27(1-2):199-208.

\section{Friedman 2002 \{published data only\}}

Friedman AS, Terras A, Glassman K. Multimodel substance use intervention program for male delinquents. Journal of Child and Adolescent Substance Abuse 2002;11(4):43-65.

\section{Glick 1987 \{published data only\}}

Glick B, Goldstein AP. Aggression replacement training. Journal of Counseling and Development 1987;65(7):356-62.

Hains-Anthony 1989 \{published data only\}

Hains AA, Herrman LP. Social cognitive skills and behavioural adjustment of delinquent adolescents in treatment. Journal of Adolescence 1989;12(3):323-8.

Kubik 2002 \{published data only\}

Kubik EK, Hecker JE, Righthand S. Adolescent females who have sexually offended: comparisons with delinquent adolescent female offenders and adolescent males who sexually offend. Journal of Child Sexual Abuse 2002;11(3):63-83.

\section{Liau 1999 \{published data only\}}

Liau AK. Evaluation of the peer helping component of a group treatment program for antisocial youth (PhD dissertation). Columbus OH: The Ohio State University, 1999. 
Martsch 2005 \{published data only\}

Martsch MD. A comparison of two group interventions for adolescent aggression: high process versus low process. Research on Social Work Practice 2005;15(1):8-18.

\section{Morrissey 1997 \{published data only\}}

Morrissey C. Multimodal approach to controlling inpatient assaultiveness among incarcerated juveniles. Journal of Offender Rehabilitation 1997;25(1/2):31-42.

Pearson 2002 \{published data only\}

Pearson FS, Lipton DS, Cleland CM, Yee DS. Effects of behavioral/cognitive-behavioral programs on recidivism. Crime \& Delinquency 2002;48(3):476-96.

\section{Sandhu 1998 \{published data only\}}

Sandhu HS. A Drug Offenders' Treatment at the Bill Johnson Correctional Center in Alva,OK by the CBTI Freedom Ranch Inc Final Evaluation (May 1998). Journal of the Oklahoma Criminal Justice Research Consortium 1998;4:1-8.

\section{Scharf 1976 \{published data only\}}

Scharf P, Hickey J. The prison and the inmate's conception of legal justice: an experiment in democratic education. Criminal Justice and Behavior 1976;3(2):107-122.

\section{Scholte 2000 \{published data only\}}

Scholte EM, Van Der Ploeg JD. Exploring factors governing successful residential treatment of youngsters with serious behavioural difficulties: findings from a longitudinal study in Holland. Childhood 2000;2:77-93.

\section{Sukhodolsy 2004 \{published data only\}}

Sukhodolsky DG, Kassinove H, Gorman BS. Cognitivebehavioral therapy for anger in children and adolescents: a meta-analysis. Aggression and Violent Behavior 2004;9:247-69.

\section{Tolan 1994 \{published data only\}}

Tolan P, Guerra N. What works in reducing adolescent violence: an empirical review of the field. Boulder, CO: Center for the Study and Prevention of Violence, 1994.

\section{Venngard 1997 \{published data only\}}

Vennard J, Sugg D, Hedderman C. Changing Offenders' Attitudes and Behaviour: What Works? (Research Findings No. 61). London: Home Office Research and Statistics Directorate, 1997.

\section{Vermeiren 2002 \{published data only\}}

Vermeiren R, Schwab-Stone M, Ruchkin V, De-Clippele A, Deboutte $\mathrm{D}$. Predicting recidivism in delinquent adolescents from psychological and psychiatric assessment. Canadian Journal of Criminology 2002;30:145-63.

\section{Welsh 1999 \{published data only\}}

Welsh W. Reducing minority overrepresentation in juvenile justice: Results of community based delinquency prevention in Harrisburg. Canadian Journal of Criminology 1999;30:145-63.
Wilkinson 2005 \{published data only\}

Wilkinson J. Evaluating evidence for the effectiveness of the reasoning and rehabilitation programme. The Howard Journal 2005;44(1):70-85.

\section{Wilson 2005 \{published data only\}}

Wilson DB, Allen LC, MacKenzie DL. A quantitative review of structured, group-oriented, cognitive-behavioral programs for offenders. Criminal Justice and Behavior 2005;32(2):172-204.

Xiaojia 2001 \{published data only\}

Xiaojia GE, Donnellan MB, Wenk E. Development of Persistent Criminal Offending in Males 2001. Canadian Journal of Criminology 2001;30:145-63.

\section{Additional references}

\section{Andrews 1990}

Andrews DA, Zinger I, Hoge RD, Bonta J, Gendreau P, Cullen FT. Does correctional treatment work? A clinically-relevant and psychologically informed meta- analysis. Criminology 1990;28:369-404

\section{Andrews 1998}

Andrews DA, Bonta J. The Psychology of Criminal Conduct. Anderson Publishing Co, 1998.

\section{Andrews 2006}

Andrews D, Bonta J. The Psychology of Criminal Conduct. Fourth Edition. Anderson Publishing Co, 2006.

\section{Antonowicz 1994}

Antonowicz DH, Ross RR. Essential components of successful rehabilitation programs for offenders. International Journal of Offender Therapy and Comparative Criminology 1994;38:97-104.

\section{Cameron 2004}

Cameron H, Telfer J. Cognitive-Behavioural Group Work: Its Application to Spesific Offender Groups. Howard Journal of Criminal Justice 2004;43(1):47-64.

\section{Cottle 2001}

Cottle CC, Lee RJ, Heilbrun K. The prediction of criminal recidivism in juveniles. Criminal Justice and Behavior 2001;28:367-94.

\section{Dishion 2006}

Dishion TJ, Dodge K.A, Lansford JE. Findings and Recommendations. A Blueprint to Minimize Deviant Peer Influence in Youth Interventions and Programs. In: Dodge KA, Dishion TJ, Lansford JE editor(s). Deviant Peer Influences in Programs for Youth. Problems and Solutions. NY, NY: The Guilford Press, 2006.

\section{Dowden 1999}

Dowden C, Andrews DA. What works in young offender treatment: A metaanalysis. Forum on Corrections Research 1999;11(2):1-6. 


\section{Dowden 2000}

Dowden DA, Andrews C. Effective correctional treatment and violent reoffending: A metaanalysis. Canadian Journal of Criminology 2000;October:449-67.

\section{Egger 1997}

Egger M, Davey Smith G, Schneider M, Minder C. Bias in metaanalysis detected by a simple, graphical test. British Medical Journal 1997;315:629-34.

\section{Elliot 1998}

Elliot D, Tolan PH. Youth violence, prevention, intervention and social policy: An overview. In: D. Flannery, R. Hoff editor(s). Youth violence: A volume in the psychiatric clinics of North America. Washington DC: American Psychiatric Association, 1998.

\section{Fisher 2000}

Fisher PA, Chamberlain P. Multidimensional Treatment Foster Care: A program for intensive parenting, family support, and skill building. Journal of Emotional and Behavioral Disorders 2000;8(3):155-64.

\section{Garrett 1985}

Garrett CJ. Effects of residential treatment on adjudicated delinquents: a meta-analysis. Journal of Research in Crime and Delinquency 1985;22:287-308.

\section{Genovés 2006}

Genovés VG, Morales LA, Sánches-Meca J. What works for serious juvenile offenders? A systematic review. Psicothema 2006;18:611-19.

\section{Goldstein 1987}

Goldstein AP, Glick B. Aggression replacement training: a comprehensive intervention for aggressive youth. Champaign, ILL: Research Press, 1987.

\section{Gundersen 2005}

Gundersen K, Finne J, Olsen TM. ART - En metode for trening av social kompetanse [Norwegian]. ART - A method for training in social competence. Rogaland Høgskole, Norway 2005.

\section{Heilbrun 2000}

Heilbrun K, Brock W, Waite D, Lanier A. Risk factors for juvenile criminal recidivism: The post-release community adustment of juvenile offenders. Criminal Justice and Behavior 2000;27(3):s $275-91$.

\section{Henggeler 1989}

Henggeler S W. Delinquency in adolescence. Sage, Newbury Park, CA., 1989.

\section{Henggeler 1996}

Henggeler SW. Treatment of Violent Juvenile Offenders - We have the knowledge. Comment on Gorman Smith et al. (1996). Journal of Family Psychology 1996;10(2):137-41.

\section{Higgins 2002}

Higgins JP, Thompson SG. Quantifying heterogeneity in a metaanalysis. Statistics in Medicine 2002;21:1539-58.

\section{Higgins 2005}

Higgins JPT, Green S, editors. Cochrane Handbook for Systematic Reviews of Interventions 4.2.5 [updated May 2005]. The Cochrane Library, Issue 3, 2005. Chichester, UK: John Wiley \& Sons, Ltd, 2005.

\section{Howell 1995}

Howell JC, Krisberg B, Jones M. Trends in juvenile crime and youth violence. In: JC Howell, B Krisberg, J Hawkins, JJ Wilson editor(s). Sourcebook in serious, violent and chronic juvenile offenders. Newbury Park, CA: Sage Publications, Inc, 1995:1-35.

\section{Izzo 1990}

Izzo R, Ross R. Meta-analysis of rehabilitation programs for juvenile delinquents: A brief report. Criminal Justice and Behavior 1990;17:134-42.

\section{Landenberger 2005}

Landenberger NA, Lipsey MW. The positive effects of cognitivebehavioral programs for offenders: A meta-analysis of factors associated with effective treatment. Journal of Experimental Criminology 2005;1(4):451-476.

\section{Lipsey 1992}

Lipsey MW. Juvenile Delinquency Treatment: A meta-analytic inquiry into the variability of effects. In: TD Cook, H Cooper, DS Cordray, H Hartmann, LV Hedges, RJ Light, TA Louis, F Mosteller editor(s). Meta-analysis for Explanation. A Casebook. New York: Russell Sage, 1992:83-127.

\section{Lipsey 1998}

Lipsey MW, Derzon JH. Predictors of violent or serious delinquency in adolescence and early adulthood: a synthesis of longitudinal research. In: R Loeber, D Farrington editor(s). Serious and violent juvenile offenders: risk factors and successful interventions. Thousand Oaks, CA: Sage Publications, 1998:86-105.

\section{Lipsey 1999}

Lipsey MW. Can intervention rehabilitate serious delinquents?. Annals of the American Academy of Political and Social Science 1999;564:142-67.

\section{Lipsey 2001}

Lipsey MW, Chapman GL, Landenberger NA. Cognitive behavioral programs for offenders. Annals of the American Academy of Political and Social Science 2001;578:144-57.

\section{Littell 2005}

Littell JH, Popa M, Forsythe B. Multisystemic Therapy for social, emotional, and behavioral problems in youth aged 10-17. Cochrane Database of Systematic Reviews 2005, Issue 4. [DOI: 10.1002/14651858.CD004797.pub4]

\section{Little 1988}

Little GL, Robinson KD. Moral reconation therapy: A systematic step-by-step treatment system for treatment resistant clients. Psychological Reports 1988;62(1):135-51. 


\section{Little 2005}

Little GL. Meta-analysis of moral reconation therapy (r): Recividism results from probation and parole implementations. Cognitive-Behavioral Treatment Review 2005;14:14-16.

\section{Loeber 1997}

Loeber R, Hay D. Key issues in the development of aggression and violence from childhood to early adulthood. Annual Review of Psychology 1997;48:371-410.

\section{Loeber 1998}

Loeber R, Farrington DP. Serious and Violent Juvenile Offenders, Risk Factors and Successful Interventions. Thousand Oaks, CA: Sage, 1998.

\section{Loeber 2000}

Loeber R, Farrington DP. Young Children who commit crime: Epidemiology, developmental origins, risk factors, early interventions, and policy implications. Development and Psychopathology 2000;12:737-62.

\section{Moffitt 1993}

Moffitt TE. Adolescence-Limited and Life-course-Persistent Antisocial Behavior. A Developmental Taxonomy. Psychological Review 1993;100:2-15.

\section{Mulvay 1993}

Mulvay EP, Arthur MA, Reppucci ND. The prevention and treatment of juvenile delinquency: A review of the research. Clinical Psychology Review 1993;13:133-67.

\section{Patterson 1993}

Patterson GR, Yoerger K. Developmental models for delinquent behavior. Crime and mental disorders. Hodgins, S.. Newbury Park, CA: Sage, 1993:140-72.

\section{Redondo 1997}

Redondo S, Carrido V, Sanchez-Meca J. What works in correctional rehabilitation in Europe: A meta-analytic review. Advances in Psychology and Law: International contributions. Berlin: De Gruyter, 1997.

\section{Redondo 1999}

Redondo S, Sànchez-Meca J, Garrido V. The influence of treatment programmes on the recidivism of juvenile and adult offenders: an European metaanalytic review. Psychology, Crime and Law 1999;5:251-78.

\section{CHARACTERISTICS OF STUDIES}

Characteristics of included studies [ordered by study ID]

\section{Ross 1985}

Ross RR, Fabiano EA. Time to think: A cognitive model of delinquency prevention and offender rehabilitation. Johnson City, TN: The Institute of Social Sciences and Arts, 1985.

\section{Rutter 1998}

Rutter M, Giller H, Hagell A. Antisocial Behavior by Young People. Cambridge: Cambridge University Press, 1998.

\section{Sallnäs 2000}

Sallnäs M. Barnavårdens institutioner - framväxt, ideologi och struktur (Rapport i socialarbejde nr 96 -2000) [Swedish]. The growth, ideology and structure of the institutions for care of children (Report in Social Work no. 96-2000). Stockholm: Stockholms Universitet, 2000.

\section{Sexton 1999}

Sexton TL, Alexander JF. Functional Family Therapy: Principles of Clinical Intervention, Assessment, and Implementation. Henderson NV: RCH Enterprises, 1999.

\section{Simourd 1994}

Simourd L, Andrews DA. Correlates of delinquency: a look at gender differences. Forum on Corrections Research 1994;6(2):26-31.

\section{Stattin 1991}

Stattin H, Magnusson D. Stability and change in criminal behaviour up to age 30: Findings from a prospective, longitudinal study in Sweden. British Journal of Criminology 1991;31:327-46.

\section{Tremblay 1999}

Tremblay RE. When Children's Social Development Fails. In: D.P. Keating, C. Hertzman editor(s). Developmental Health and The Wealth of Nations: Social, Biological and Educational Dynamics. New York: Guilford Press, 1999.

\section{Wolf 1995}

Wolf MM, Kirgin KA, Fixen DL, Blase KA, Braukman CJ. The Teaching-family model: A case study in data-based program development and refinement (and dragon wrestling). Journal of Organizational Behaviour Management 1995;15(1/2):11-38.

* Indicates the major publication for the study

Armstrong 2003

\begin{tabular}{ll}
\hline Methods & RCT \\
\hline Participants & 256 male residents incarcerated between 1997 and 1998. Age from 15-22 years (M=20.21). \\
\hline Interventions & $\begin{array}{l}\text { Experimental group ( } \mathrm{n} \text { randomized }=129): \text { Moral Reconation Therapy (MRT) delivered as three lectures } \\
\text { lasting } 1-1,5 \text { hrs /week plus daily exposure to MRT in the form of comments on daily behaviour. Average } \\
\text { treatment length is } 77 \text { days. }\end{array}$ \\
\hline
\end{tabular}


Armstrong 2003 (Continued)

Control group ( $\mathrm{n}$ randomized $=127$ ): The "general population" within the jail. Nothing is mentioned about what treatment the controls were getting. Average treatment length was 66 days.

\begin{tabular}{ll}
\hline Outcomes & $\begin{array}{l}\text { Survival analyses were used to examine treatment and control group differences in the risk of recidi- } \\
\text { vism. The survival curve shows probability of post-release survival up to } 800 \text { days in blocks of } 30 \text { days. }\end{array}$ \\
\hline Notes & $\begin{array}{l}\text { The randomization was not implemented in allocation to treatment since } 19 \text { youth randomized to the } \\
\text { experimental group were never placed in the experimental treatment facility and } 25 \text { control partici- } \\
\text { pants received the experimental treatment. Evaluator is independent researcher. No allegiance - } 0 .\end{array}$
\end{tabular}

\section{Risk of bias}

\begin{tabular}{lll}
\hline Bias & Authors' judgement & Support for judgement \\
\hline Allocation concealment? & Unclear risk & D - Not used \\
\hline
\end{tabular}

\section{Bottcher 1985}

\begin{tabular}{|c|c|}
\hline Methods & Quasi-experiment with matched comparison group \\
\hline Participants & Girls 82 girls with relatively long prior records (>7 y) and fairly serious offenses. Age average was 15 . \\
\hline Interventions & $\begin{array}{l}\text { Experimental group ( } \mathrm{n}=44) \text { : Situational Decision-Making Model (SDM) intended to improve thinking and } \\
\text { problem solving skills among incarcerated girls. Guided peer group counseling sessions were designed } \\
\text { to teach girls how to make rational, informed decisions concerning individual and interpersonal needs } \\
\text { to keep them out of trouble.SDM was scheduled for } 16 \mathrm{~h} / \mathrm{w} \text {. SDM consists of three types of groupmeet- } \\
\text { ings: Acountability groups, agenda or decision making and evaluation groups. Average length of stay at } \\
\text { the time of the study was } 3.5 \text { months with a range of } 1-7 \text { months. Total time of intervention estimated } \\
\text { to be } 224 \text { hours. } \\
\text { Control group ( } n=38) \text { : Girls from the same unit before implementation of the experimental program. }\end{array}$ \\
\hline
\end{tabular}

Outcomes Arrests from the booking records in the Fresno County Juvenile Hall and California Department of Justice's Bureau of Identification. Time is exactly 18 months after current booking (includes treatment time, f-up 13-17m). Interviews with staff and girls were also made to assess the program implementation and outcome.

\section{Notes}

Quasi-experimental design with historical comparisons matched for offenses and age at current offense. Author is evaluator from authority - allegiance rating 1.

\section{Risk of bias}

\begin{tabular}{lll}
\hline Bias & Authors' judgement & Support for judgement \\
\hline Allocation concealment? & Unclear risk & D - Not used \\
\hline
\end{tabular}

Cann 2003

\begin{tabular}{ll}
\hline Methods & Quasi-experiment with matched comparison cases \\
\hline Participants & $3068\left(2^{\star} 1534\right)$ men below 21 years of age at sentencing. \\
\hline Interventions & $\begin{array}{l}\text { Experimental group }(\mathrm{n}=1534): \text { Enhanced Thinking Skills (ETS) or Reasoning and Rehabilitation }(\mathrm{R} \& \mathrm{R}) \\
\text { are two different programs that were introduced in } 1992 . \text { The purpose was to teach offenders how to }\end{array}$
\end{tabular}


Cann 2003 (Continued)

think in order to avoid patterns of thinking which lead them to offend. ETS consists of 22 two-hour sessesions and R\&R consists of 38 two-hour sessions.

Control group ( $n=1534)$ : Regular prison programs without CBT but no further definition.

\begin{tabular}{ll}
\hline Outcomes & One and two-year reconviction rates collected from the Offender's index, a Home Office database. \\
\hline Notes & $\begin{array}{l}\text { Very large study with good analyses of ITT and TOT. A separation of ETS and R\&R does not give any oth- } \\
\text { er result in the present analyses. Authors are not involved but represent authority - allegiance rating } 0 .\end{array}$
\end{tabular}

\section{Risk of bias}

\begin{tabular}{lll}
\hline Bias & Authors' judgement & Support for judgement \\
\hline Allocation concealment? & Unclear risk & D - Not used \\
\hline
\end{tabular}

\section{Deschamps 1998}

\begin{tabular}{|c|c|c|}
\hline Methods & \multicolumn{2}{|c|}{ Quasi-experiment with comparison group from similar facility but no CBT } \\
\hline Participants & \multicolumn{2}{|c|}{$268(2 \times 134)$ men $16-21$ years of of age. } \\
\hline Interventions & \multicolumn{2}{|c|}{$\begin{array}{l}\text { Experimental group ( } n=134) \text { : Moral Reconation Therapy is a systeamtic, step-by step treatment strategy } \\
\text { designed to enhance self image, promote growth of a positive, productive identity and facilitate the de- } \\
\text { velopment of higher levels of moral reasoning. The focus is on criminogenic thoughts and consists of } 9 \\
\text { levels and } 16 \text { steps. Time of treatment varied between } 1 \text { and } 180+\text { days depending of sentence length. } \\
\text { Three months seems to be the average so an estimate of time of intervention is } 120 \text { hours. } \\
\text { Control group }(n=134) \text { : A random sample from another but similar prison without MRT. }\end{array}$} \\
\hline Outcomes & \multicolumn{2}{|c|}{$\begin{array}{l}\text { Recidivism measured through the Offender Management System. Charged and convicted after dis- } \\
\text { charge or escaped from the facility. Time after discharge was minimum 1year and } 4 \text { months during a 2- } \\
\text { year period, but could have been up to one year more for some. }\end{array}$} \\
\hline Notes & \multicolumn{2}{|c|}{$\begin{array}{l}\text { A number of hypotheses regarding the importance of attachment, significance of step level etc were al- } \\
\text { so investigated. All data came from records and the author had no direct contact with the facilities. } \\
\text { A Masters thesis. Author not involved in treatment or implementation - allegiance rating } 0 \text {. }\end{array}$} \\
\hline \multicolumn{3}{|l|}{ Risk of bias } \\
\hline Bias & Authors' judgement & Support for judgement \\
\hline Allocation concealment? & Unclear risk & D - Not used \\
\hline
\end{tabular}

\section{Drake 2005}

\begin{tabular}{ll}
\hline Methods & Quasi-experiment with historical comparison group from same institution but prior to intervention. \\
\hline Participants & $125(63+65)$ participants with mental health problems. 15 years of age on admission (average) \\
\hline Interventions & $\begin{array}{l}\text { Experimental group }(\mathrm{n}=63): \text { Dialectical Behavior Therapy (DBT) applied to offenders with mental health } \\
\text { problems. It focuses on improving behavioural skills, motivation to change dysfunctional behaviours } \\
\text { and ensurance to use the new skills in the daily institutional life. } \\
\text { Control group }(n=65): \text { Treated at the same institution before introduction of DBT. Not specified with re- } \\
\text { spect to content. }\end{array}$
\end{tabular}


Drake 2005 (Continued)

Outcomes

Recidivism was defined as any offense committed after release to the community that results in a conviction. Recidivism is reported for each 6 month period up until 36 months. Total recidivism is used in the present analyses.

Notes The evaluation is made by an independent public policy institute and was not involved in the implementation or administration of the DBT. Allegiance not present - 0 .

\section{Risk of bias}

\begin{tabular}{lll}
\hline Bias & Authors' judgement & Support for judgement \\
\hline Allocation concealment? & Unclear risk & D - Not used \\
\hline
\end{tabular}

Farrington 2002

\begin{tabular}{|c|c|}
\hline Methods & Quasi-experiment with comparison group. \\
\hline Participants & $314(184+130)$ men $18-21$ years of age. \\
\hline Interventions & $\begin{array}{l}\text { Experimental group ( } n=184) \text { : The High Intensity Training (HIT) program combined elements of Army } \\
\text { life with a rehabilitative regime and consisted of a } 25 \text { week regime comprising five phases of five weeks. } \\
\text { After an initial assessment phase there was a basic skills training phase including basic life and social } \\
\text { skills training. The third phase consisted of vocational training and the fourth focused on pre-release is- } \\
\text { sues such as challenging justifications for crime. The fifth phase comprised a work or training period in } \\
\text { the community but return to camp during weekends. Estimated time of intervention is } 500+\text { hours. } \\
\text { Control group ( } n=130) \text { : Drawn from other prisons. }\end{array}$ \\
\hline
\end{tabular}

\begin{tabular}{ll}
\hline Outcomes & Reconvictions were obtained from the Police National Computer at one and two year follow-up. \\
\hline Notes & $\begin{array}{l}\text { This study is problematic because of significant initial differences between the groups. Authority report } \\
\text { and not published in journal. Author comes from authority - allegiance rating } 0 .\end{array}$ \\
\hline
\end{tabular}

\section{Risk of bias}

\begin{tabular}{lll}
\hline Bias & Authors' judgement & Support for judgement \\
\hline Allocation concealment? & Unclear risk & D - Not used \\
\hline
\end{tabular}

\section{Greenwood 1993}

\begin{tabular}{ll}
\hline Methods & RCT \\
\hline Participants & $\begin{array}{l}150 \text { men, } 15-17 \text { years of age who were expected to stay in prison for at least one year. Of the } 75 \text { experi- } \\
\text { mental participants, } 17(23 \%) \text { were removed for disciplinalry reasons after } 145 \text { days. Of those who com- } \\
\text { pleted the one-year term, } 27 \% \text { did not move through all three phases of the residential program. The } \\
\text { average length of stay for all experimental participants was } 327 \text { and } 360 \text { for those in the control group. }\end{array}$
\end{tabular}

Interventions

Experimental group ( $n=75$ ): PCYC a comprehensive program based on Positive Peer Culture, Glasser's reality therapy and Yochelson and Samenows criminal thinking errors. Built on the status of knowledge at that time, including focus on dynamic risk factors. The program consisted of successive phases ending with part-time work in a variety of premises such as farming, woodworking and auto repair. Frequent contacts following release.Eligible youths were randomly assigned to PCYC or control who were 
placed in training schools in Ohio. Interviews showed that the culture at PCYC was experienced as more positive than at the training schools. Estimated time of intervention is $500+$ hours.

Control group ( $n=75)$ : From two other training schools which are well described and youths' experience of the different cultures are presented.

Outcomes

Evaluated independently by RAND, who also conducted randomization blindly. Did the youth assigned to the intervention receive better treatment? Was the recidivism rate lower? Data was available in the form of 149 background files, 148 initial interviews and 146 exit interviews with case-workers. At the end of data-collection one was still in placement and one was still "absent without leave". Outcome analyses focused on 148 out of 150 youths. Analyses of pre-treatment data showed only minor differences between experimental and control samples. Outcomes were official court records of arrests, selfreports of delinquency and drug use one year after release. Analyses are made separately for ITT and TOT. Survival analyses are presented.

Notes

RCT study where randomization seems to have taken place at the authority level above the institutions. Interviews with participants and staff. Follow-up information from interview and juveniles and adult court records for 12 months after release. Author comes from an independent evaluation corporation allegiance rating 0 .

\begin{tabular}{lll}
\hline Risk of bias & \\
\hline Bias & Authors' judgement & Support for judgement \\
\hline Allocation concealment? & Low risk & A - Adequate \\
\hline
\end{tabular}

Guerra 1990

\begin{tabular}{ll}
\hline Methods & RCT study with three arms. \\
\hline Participants & $\begin{array}{l}\text { Adolescents 15-18 years of age, mean 17:2. Initially } 171 \text { eligible Ss indicated interest to participate, } 165 \\
\text { participated in pre-tests and were randomized (balanced by gender). To establish equal group sizes } \\
(3 \times 40), 6 \text { of the } 126 \text { participants who completed posttest and training were eliminated through random } \\
\text { selection. Thus the final sample consisted of } 20 \text { boys and } 20 \text { girls in each of the three groups. }\end{array}$ \\
\hline
\end{tabular}

Interventions $\quad$ Experimental group $(n=40)$ : 12 group sessions (weeks) of Cognitive Mediation Training, CMT, was administered in groups of $12-14$ adolescents with no more than $60 \%$ of either males or females. Training techniques were limited to instruction and structured discussion in order to be comparable to the control conditions. The focus was on problem solving and handling of agression and not specifically on criminal behavior. Total time of intervention is estimated to be 60 hours.

Control group $(n=40)$ : No treatment but participation in pre- and post testing. Regular treatment seems to be school activities in the same format as the experimental group.

Alternative treatment group ( $n=40)$ : Attention control by practicing basic skills like reading comprehension and basic math.

Outcomes Recidivsm was collected for at least 12 and up to 2 years post release from the central data files of the state correctional agency. It was defined as revocation of parole and return to juvenile facility because of unsatisfactory behavior or a conviction resulting in adult status probation or confinement. Data is presented for 0-10 months and for 11-24 months and total 0-24 months.

Measures on social cognition, behavior ratings and self-report of training effects were also collected.

Notes An attempt to make a RCT study, but problems with attrition (about $30 \%$ of the 120 studied and more than $50 \%$ of the 165 randomized) and unclear allocation sequence reduces the quality. A TOT analysis is possible, but only on 120 out of 126 completers. Author involved in all steps - allegiance rating 4 . A problematic study due to the handling of attrition.

\section{Risk of bias}


Guerra 1990 (Continued)

\begin{tabular}{lll} 
Bias & Authors' judgement & Support for judgement \\
\hline Allocation concealment? & High risk & C-Inadequate \\
\hline
\end{tabular}

\section{Leeman 1993}

Methods RCT study with two control groups.

Participants

57 boys from a medium-security correctional facility in mid-Western USA housing 200 boys $15-18$ years of age. Average commitment time was 6 months. Study participants were consecutive admittees. Eighteen were assigned to each of the three (1 experimental and 2 control) groups. However, recidivism was reported for 57 rather than 54 participants since 3 were replaced after randomization since they were later found not to fulfill inclusion criteria but could not be excluded from intervention .

Interventions $\quad$ Experimental group $(n=20)$ : EQUIP assimilates the social skills training, anger management and moral education components or ART into a modified Positive Peer Culture (PPP) group culture format. In regular PPP meetings 1-1.5 h/day peers try to help one-another, but they lack social skills. Therefore EQUIP-meetings are modified with components from ART on two of the weekly meetings. Total time of intervention is 6 months, i.e. 270 hours.

Simple Control group ( $n=19)$ : Only participated in pre- and post tests and received training designed by their respective social workers and was not standardised among participants.

Motivational Control group ( $\mathrm{n}=18)$ : Same as the simple control group, but received a five minute motivational instruction immediately following the pretsting.

Outcomes Recidivism data post-release were archival and in addition there was self-reported misconduct data. Other outcomes were self reported moral judgment and social skills. Recidivism was measured at 6 and 12 months post-release. Social skills and self-reported misconduct were also used as outcomes during the incarceration but not at post-test. Staff rated misconduct was registered throughout the stay.

\begin{tabular}{|c|c|}
\hline Notes & $\begin{array}{l}\text { Very good study but no allocation concealment and inclusion criteria violation of the three replaced } \\
\text { participants. Published in journal. Authors clearly involved in invention and implementation - alle- } \\
\text { giance rating } 3 \text {. }\end{array}$ \\
\hline
\end{tabular}

\section{Risk of bias}

\begin{tabular}{lll}
\hline Bias & Authors' judgement & Support for judgement \\
\hline Allocation concealment? & Unclear risk & B - Unclear \\
\hline
\end{tabular}

\section{Robinson 1994}

\begin{tabular}{ll}
\hline Methods & Quasi-experiment with historical comparison group from the same institution but prior to intervention. \\
\hline Participants & $\begin{array}{l}143 \text { men and women (3\%). 14-18 years of age. } 6 \text { controls were eliminated because all of their files were } \\
\text { not available. An unknown number in the experimental group were not included because they did not } \\
\text { attend at least } 90 \% \text { of the sessions or failed the curriculum. }\end{array}$ \\
\hline Interventions & $\begin{array}{l}\text { Experimental group }(n=73): \text { A cognitive skills curriculum, the Reasoning and Rehabilitation Model of } \\
\text { Ross and Fabiano, was implemented for three hours each week for } 8 \text { weeks by trained teachers. } \\
\text { Control group }(n=70): \text { Residents of the center prior to implementation othe cognitive skills curriculum. }\end{array}$
\end{tabular}

\section{Outcomes}

Recidivism was measured by the juvenile court records up to six months after release. 
Robinson 1994 (Continued)

For the treatment group three other instruments were used (Watson-Glaser Critical Thinking Appraisal,

California Psychological Inventory, Raven's Progressive Matrices)

Notes

Only completers are reported and an unknown number of experimental participants have been excluded. Data is available only for six months follow-up. Author seems to have been collecting data but not directly involved in treatment implementation. Allegiance 2 .

\section{Risk of bias}

\begin{tabular}{lll}
\hline Bias & Authors' judgement & Support for judgement \\
\hline Allocation concealment? & Unclear risk & D - Not used \\
\hline
\end{tabular}

Sarason 1973

$\begin{array}{ll}\text { Methods } & \begin{array}{l}\text { Quasi-experiment with three comparison groups. "Essentially random assignment but occasionally in- } \\ \text { fluenced by weekly admission rates". }\end{array}\end{array}$

Participants

192 male offenders between 15.5 and 18 years of age, mean 16:7. There were 64 Ss in each of the three groups. All participants were committed to Cascadia Juvenile Reception-diagnstic Center in Tacoma, Washington for a period of six weeks, but later transferred to other facilities.

Interventions Expeimental group ( $n=64)$ : Social modeling, influenced by Bandura, of behavior through role-playing and discussions led by trained instructors (graduate students). 14 hour-long sessions followed by enactment and role play by the boys. All within 4 weeks.

Control group ( $n=64)$ : No-treatment control condition at the same facility, not furhter specified. Alternative treatment group $(n=64)$ : Same format as experimental group but only group discussion and no modeling behaviour or role play.

\section{Outcomes}

Recidivism was defined as a) return of a boy to a juvenile institution b) conviction in superior court c) confinement to adult correcional institution. The period at risk was at least 18 months. In general recidivism was measured almost three years since admission. There seems to have been two periods of 12 months each, but only the whole period is reported.

Several tests were used as repeated measures (Self-description, self-concept, goal scale, activity preference questionnaire and internalization-externalization). The author had a special interest in test anxiety.

Notes

This is a very interesting early study. Well done with a lot of pioneer work both with respect to interventions and research methods. Unfortunately, the randomization was not fully implemented which makes it a quasi-experimental study with two interventions and a control group.

\section{Risk of bias}

\begin{tabular}{lll}
\hline Bias & Authors' judgement & Support for judgement \\
\hline Allocation concealment? & High risk & C - Inadequate \\
\hline
\end{tabular}

\section{Shivrattan 1988}

\begin{tabular}{ll}
\hline Methods & RCT with three arms. \\
\hline Participants & $\begin{array}{l}45 \text { new boy arrivals, } 15-17 \text { years of age, automatically fell into the randomization system with three } \\
\text { groups and another randomization to two teachers for the two treatment groups }\end{array}$ \\
\hline
\end{tabular}


Shivrattan 1988 (Continued)

Interventions
Experimental group $(n=15)$ : Social Interactional Skills Program is a highly structured didactic program. Particpants are encouraged to recall past experiences which were problematic. Followed by systematic desensitization and cognitive reappraisal and experimenting with new behaviours. Total time of intervention is 8 hours plus homework assignments - estimated time is 20 hours.

Control group ( $n=15)$ : Treatment as usual at the same school

Alternative treatment group $(n=15)$ : Stress management in the form of progressive relaxation as a means of reducing stress. Provided by two teachers for $8 \star 1$ hour individual sessions.

Recidivism was measured 12-15 months after release: Defined as a) charged and sentenced to an institution, b) those who were reported to be unsuccessful in their placement and were engageing in criminal activity but had not yet been apprehended.

Additional outcomes were MMPI, Jesness Behaviour checklist: Observer and Self Appraisal forms.

Rotes
assessment of intial equivalence, but the results of this analysis are not reported. Analysis of covari-
ance was used for outcomes.
Inventors served as supervisors for research - allegiance rating 3.

\section{Risk of bias}

\begin{tabular}{lll}
\hline Bias & Authors' judgement & Support for judgement \\
\hline Allocation concealment? & Unclear risk & B - Unclear \\
\hline
\end{tabular}

Characteristics of excluded studies [ordered by study ID]

\begin{tabular}{|c|c|}
\hline Study & Reason for exclusion \\
\hline Arnold 2003 & No criminal outcome \\
\hline Bailey 2004 & No criminal outcome \\
\hline Escamilla 1998 & No residential setting \\
\hline Friedman 2002 & No climinal outcome \\
\hline Glick 1987 & No criminal outcome \\
\hline Hains-Anthony 1989 & No criminal outcome \\
\hline Kubik 2002 & No residential setting \\
\hline Liau 1999 & No criminal outcome \\
\hline Martsch 2005 & No residential setting \\
\hline Morrissey 1997 & No criminal outcome \\
\hline Pearson 2002 & No adolescents \\
\hline Sandhu 1998 & No adolescents \\
\hline Scharf 1976 & No adolescents \\
\hline
\end{tabular}




\begin{tabular}{ll}
\hline Study & Reason for exclusion \\
\hline Scholte 2000 & No criminal outcome \\
\hline Sukhodolsy 2004 & A review \\
\hline Tolan 1994 & A review \\
\hline Venngard 1997 & A review \\
\hline Vermeiren 2002 & No residential setting \\
\hline Welsh 1999 & No residential setting \\
\hline Wilkinson 2005 & No adolescents \\
\hline Wilson 2005 & A review \\
\hline Xiaojia 2001 & No comparison group \\
\hline
\end{tabular}

\section{DATA AND ANALYSES}

\section{Comparison 1. Recidivism at 6 months: CBT vs. Control}

\begin{tabular}{lllll}
\hline Outcome or subgroup title & $\begin{array}{l}\text { No. of } \\
\text { studies }\end{array}$ & $\begin{array}{l}\text { No. of } \\
\text { partici- } \\
\text { pants }\end{array}$ & Statistical method & Effect size \\
\hline 1 Results at 6 months & 4 & 560 & Odds Ratio (M-H, Fixed, 95\% Cl) & $0.87[0.61,1.25]$ \\
\hline 1.1 RCT & 3 & 417 & Odds Ratio (M-H, Fixed, 95\% Cl) & $0.84[0.55,1.28]$ \\
\hline 1.2 Non-RCT & 1 & 143 & Odds Ratio (M-H, Fixed, 95\% Cl) & $0.96[0.49,1.86]$ \\
\hline
\end{tabular}

Analysis 1.1. Comparison 1 Recidivism at 6 months: CBT vs. Control, Outcome 1 Results at 6 months.

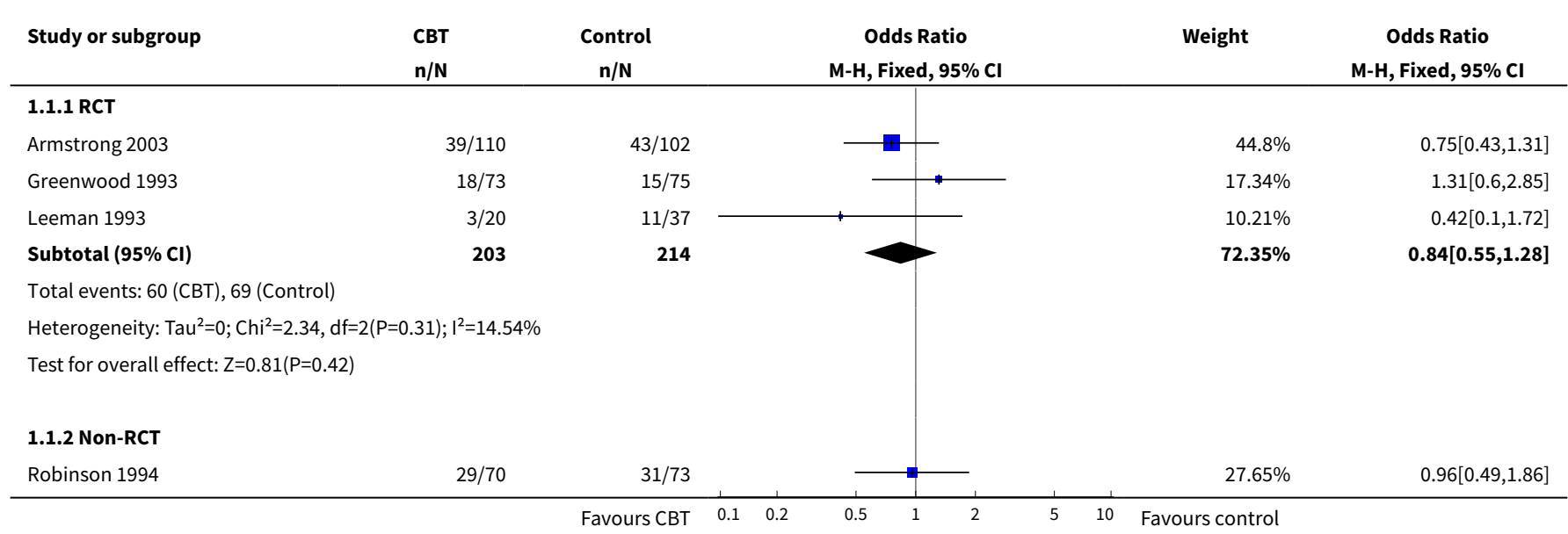




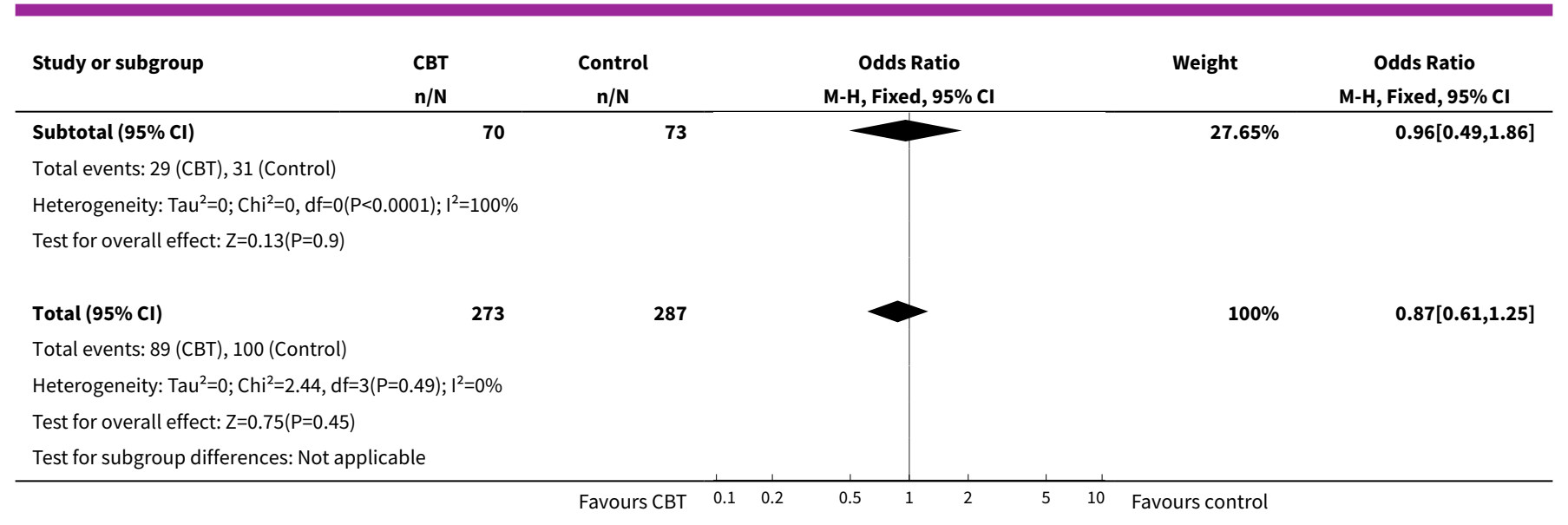

\section{Comparison 2. Recidivism at 12 months: CBT vs. Control}

\begin{tabular}{|c|c|c|c|c|}
\hline Outcome or subgroup title & $\begin{array}{l}\text { No. of } \\
\text { studies }\end{array}$ & $\begin{array}{l}\text { No. of } \\
\text { partici- } \\
\text { pants }\end{array}$ & Statistical method & Effect size \\
\hline $\begin{array}{l}112 \text { months: } \text { Dropouts }=\text { Propor }- \\
\text { tional }\end{array}$ & 10 & 4441 & Odds Ratio (M-H, Random, $95 \% \mathrm{Cl})$ & $0.69[0.53,0.90]$ \\
\hline $1.1 \mathrm{RCT}$ & 5 & 573 & Odds Ratio (M-H, Random, 95\% Cl) & $0.71[0.48,1.04]$ \\
\hline 1.2 Non-RCT & 5 & 3868 & Odds Ratio (M-H, Random, $95 \% \mathrm{Cl})$ & $0.69[0.47,1.01]$ \\
\hline 212 months: Dropouts $=$ None & 10 & 4441 & Odds Ratio (M-H, Random, 95\% Cl) & $0.68[0.52,0.90]$ \\
\hline $2.2 \mathrm{RCT}$ & 5 & 573 & Odds Ratio (M-H, Random, 95\% Cl) & $0.69[0.44,1.06]$ \\
\hline 2.3 Non-RCT & 5 & 3868 & Odds Ratio (M-H, Random, 95\% Cl) & $0.68[0.46,1.00]$ \\
\hline 312 months: Dropouts = All & 10 & 4441 & Odds Ratio (M-H, Random, 95\% Cl) & $0.75[0.61,0.94]$ \\
\hline $3.1 \mathrm{RCT}$ & 5 & 573 & Odds Ratio (M-H, Random, 95\% Cl) & $0.72[0.49,1.07]$ \\
\hline 3.2 Non-RCT & 5 & 3868 & Odds Ratio (M-H, Random, 95\% Cl) & $0.75[0.56,1.01]$ \\
\hline $\begin{array}{l}412 \text { months: Proportion Farring- } \\
\text { ton excluded }\end{array}$ & 9 & 4127 & Odds Ratio (M-H, Random, 95\% Cl) & $0.81[0.67,0.98]$ \\
\hline $4.1 \mathrm{RCT}$ & 5 & 573 & Odds Ratio (M-H, Random, 95\% Cl) & $0.71[0.48,1.04]$ \\
\hline 4.2 Non-RCT & 4 & 3554 & Odds Ratio (M-H, Random, 95\% Cl) & $0.85[0.67,1.07]$ \\
\hline $\begin{array}{l}512 \text { months: Dropouts propor- } \\
\text { tional excluding Guerra and Far- } \\
\text { rington }\end{array}$ & 8 & 4047 & Odds Ratio (M-H, Random, 95\% Cl) & $0.80[0.65,1.00]$ \\
\hline $5.1 \mathrm{RCT}$ & 4 & 493 & Odds Ratio (M-H, Random, 95\% Cl) & $0.67[0.41,1.11]$ \\
\hline 5.2 Non-RCT & 4 & 3554 & Odds Ratio (M-H, Random, 95\% Cl) & $0.85[0.67,1.07]$ \\
\hline
\end{tabular}


Analysis 2.1. Comparison 2 Recidivism at 12 months: CBT vs. Control, Outcome 112 months: Dropouts = Proportional.

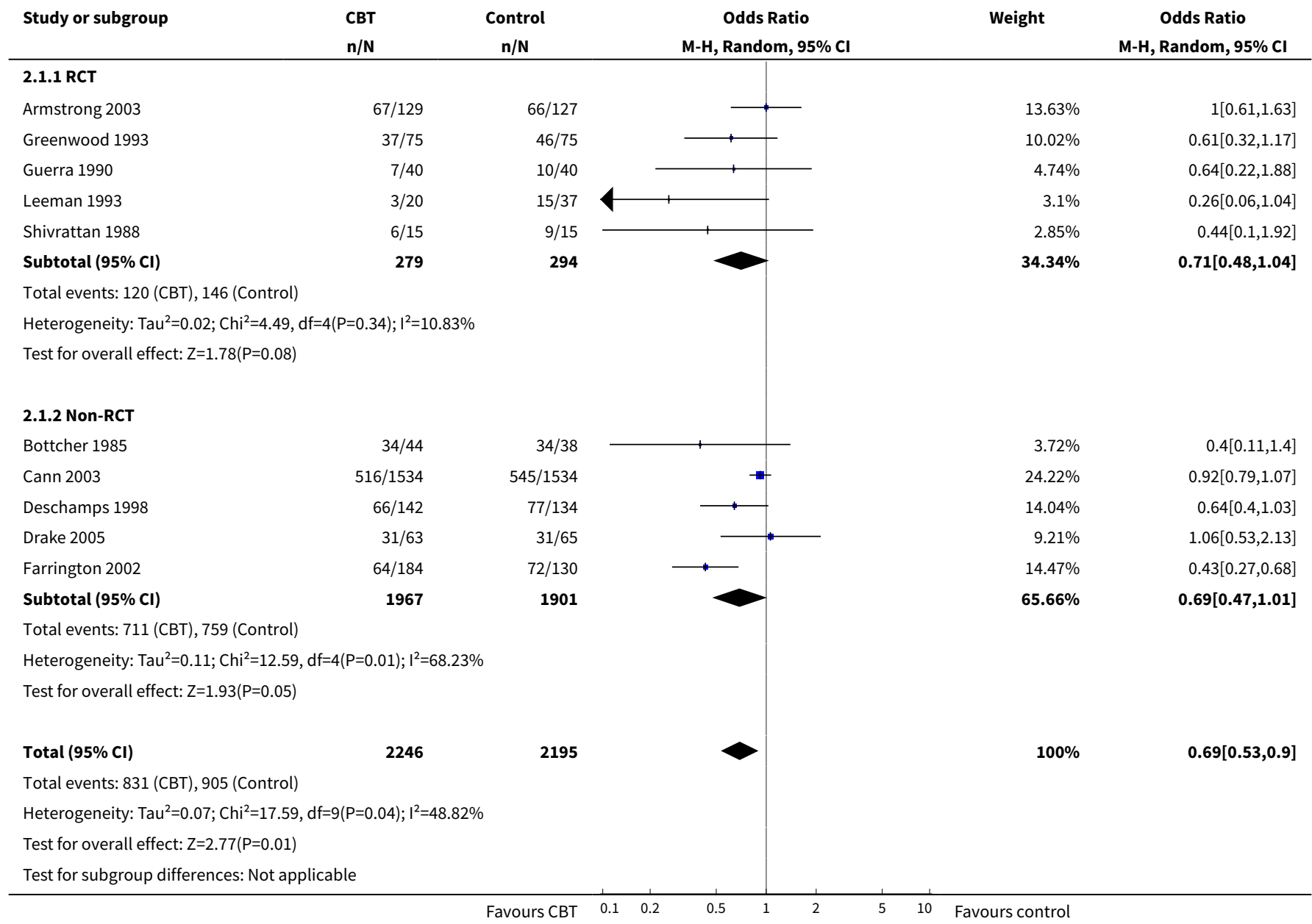

\section{Analysis 2.2. Comparison 2 Recidivism at 12 months: CBT vs. Control, Outcome 212 months: Dropouts = None.}

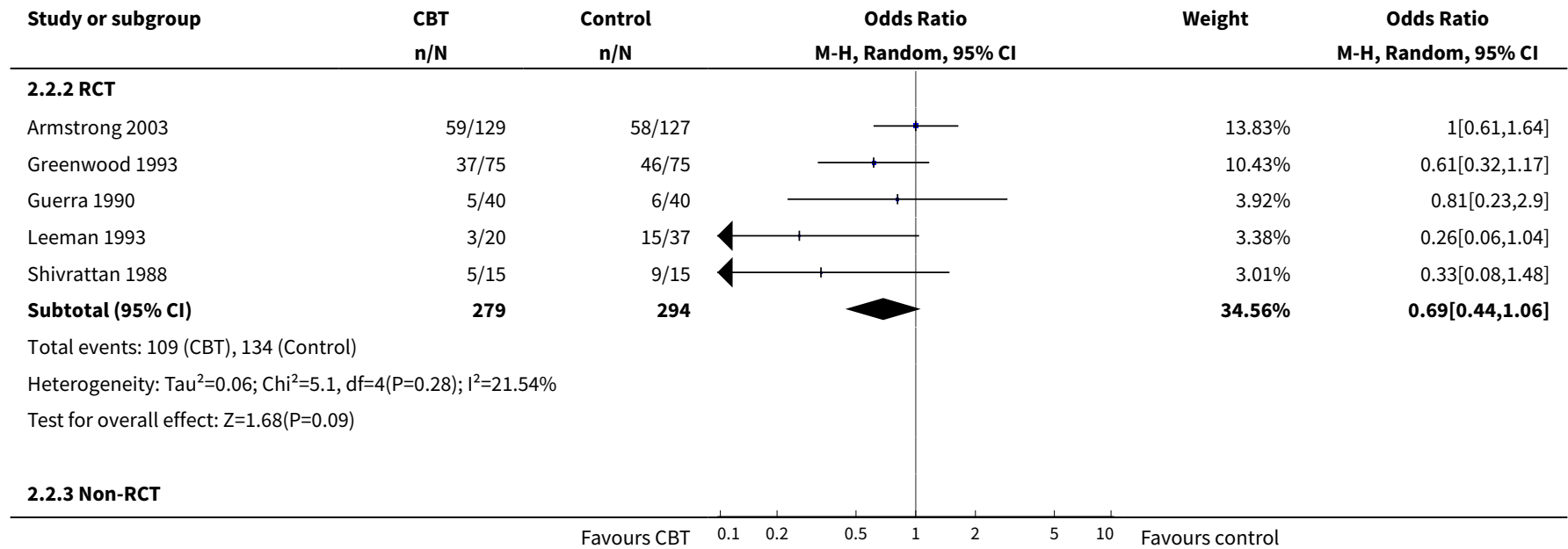




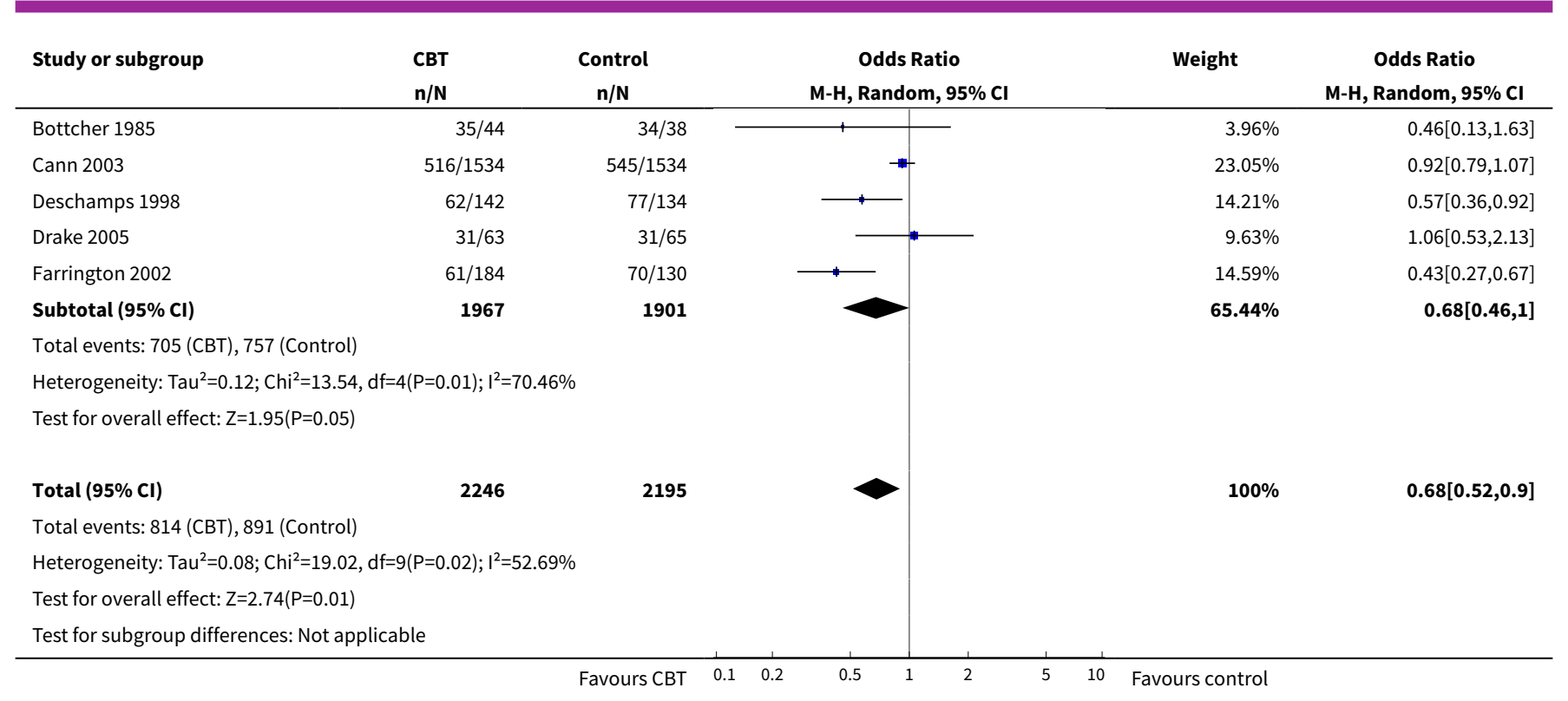

Analysis 2.3. Comparison 2 Recidivism at 12 months: CBT vs. Control, Outcome 312 months: Dropouts = All.

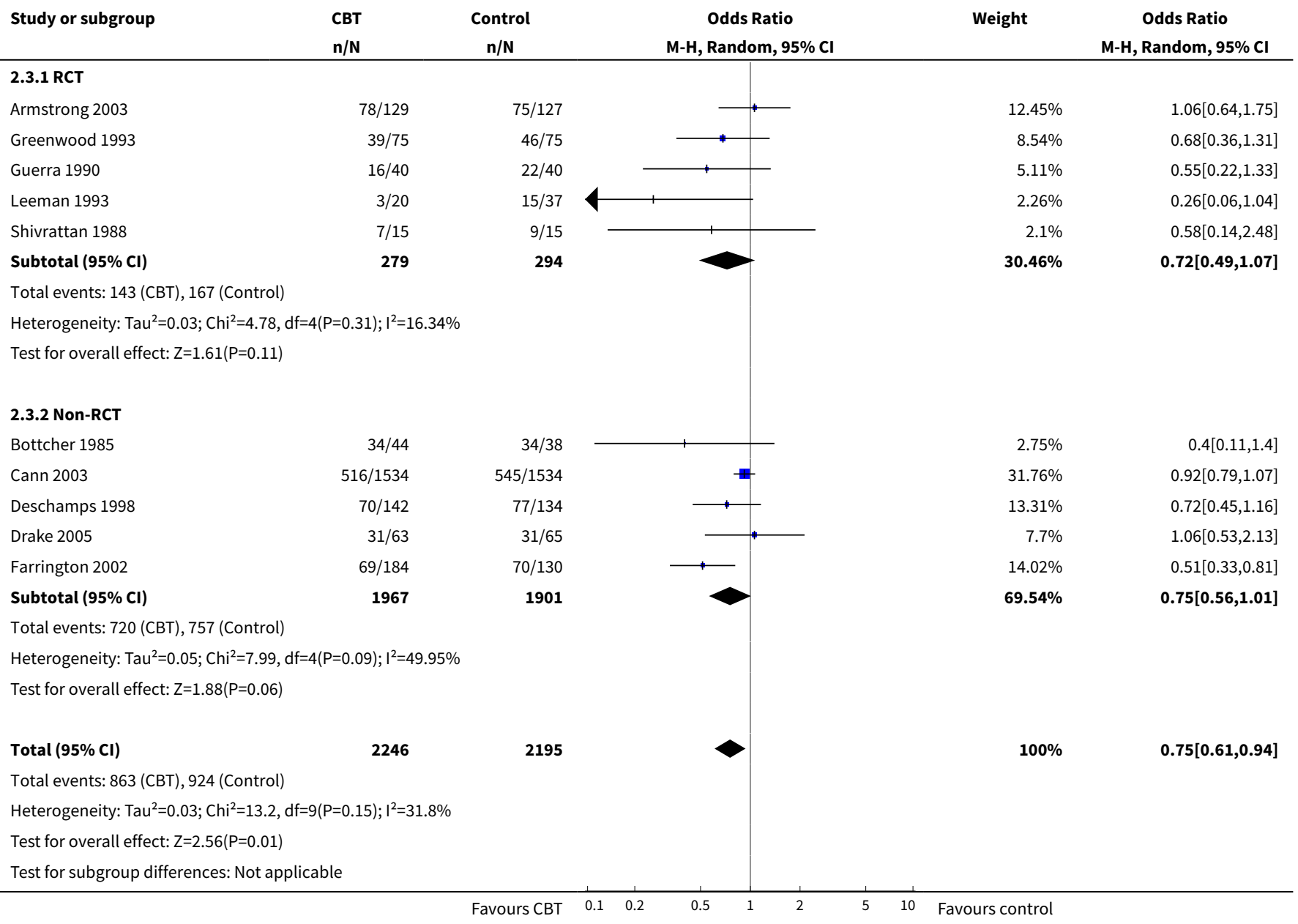


Analysis 2.4. Comparison 2 Recidivism at 12 months: CBT vs.

Control, Outcome 412 months: Proportion Farrington excluded.

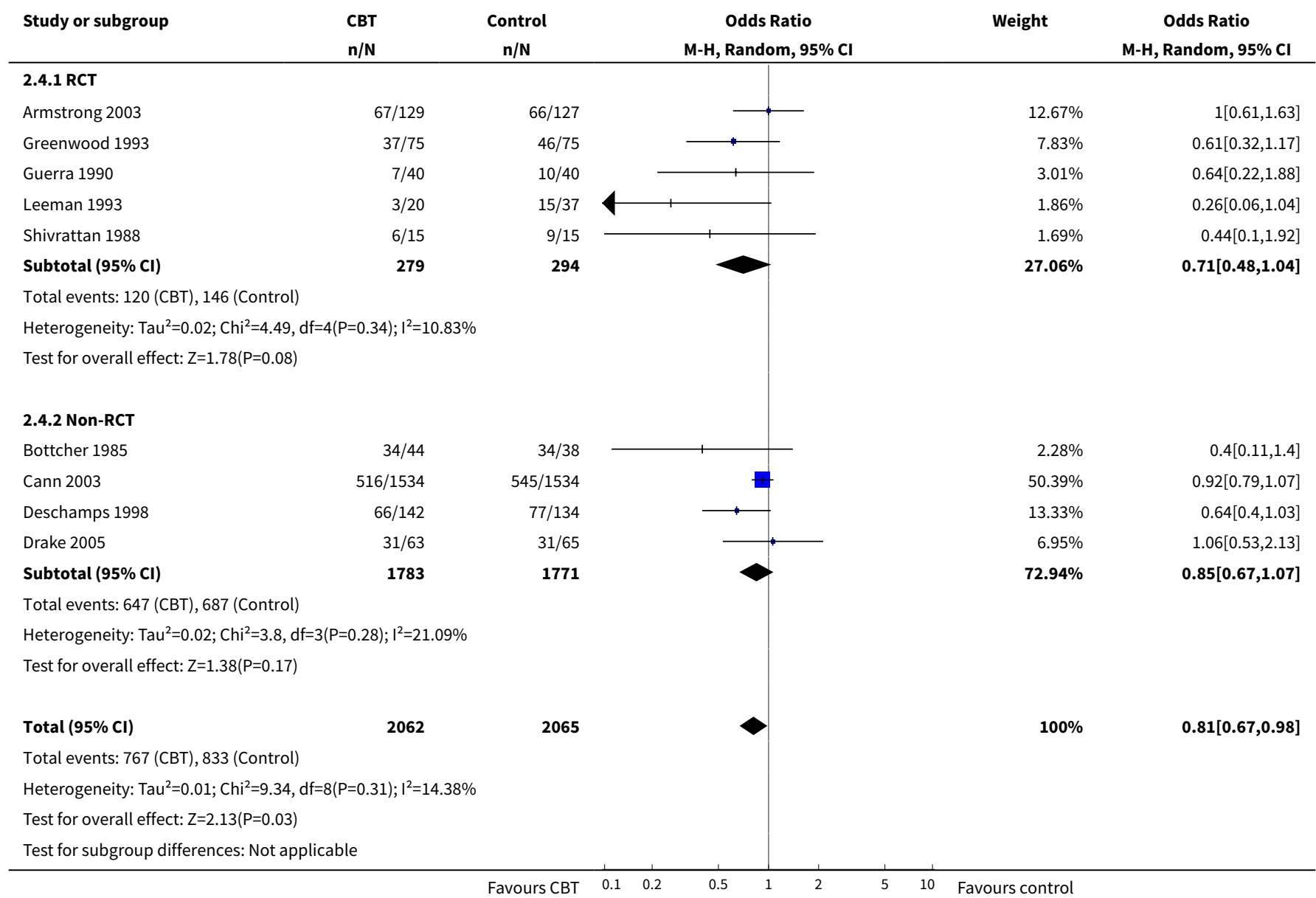

Analysis 2.5. Comparison 2 Recidivism at 12 months: CBT vs. Control, Outcome 512 months: Dropouts proportional excluding Guerra and Farrington.

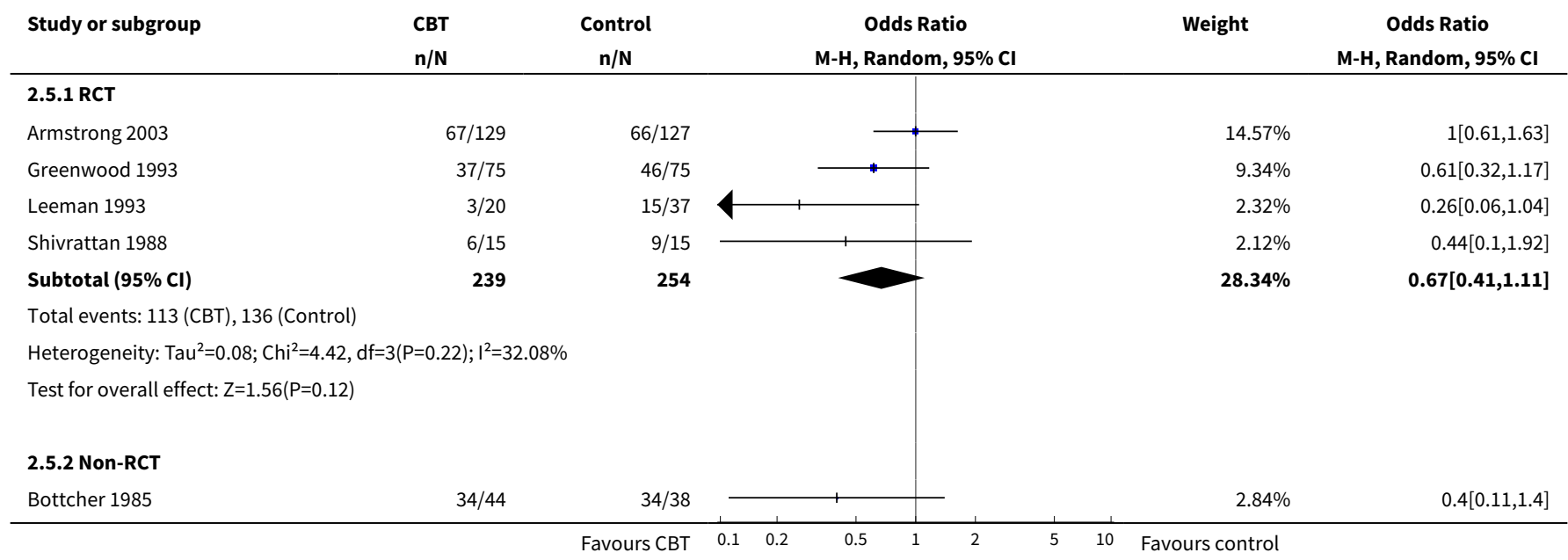




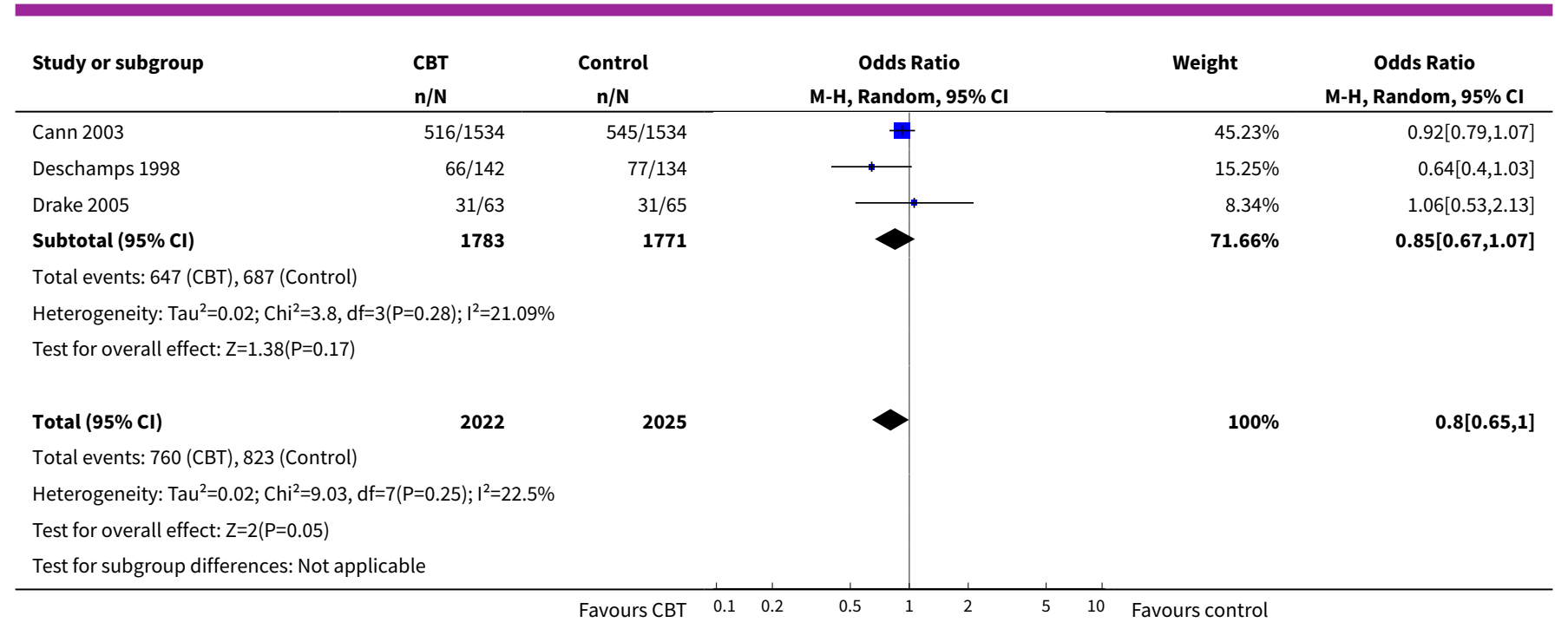

\section{Comparison 3. Recividism at 24 months: CBT vs control}

\begin{tabular}{lllll}
\hline Outcome or subgroup title & $\begin{array}{l}\text { No. of } \\
\text { studies }\end{array}$ & $\begin{array}{l}\text { No. of } \\
\text { partici- } \\
\text { pants }\end{array}$ & Statistical method & Effect size \\
\hline 124 months: Proportional & 6 & 2692 & Odds Ratio (M-H, Random, 95\% Cl) & $0.83[0.68,1.02]$ \\
\hline $1.1 \mathrm{RCT}$ & 2 & 336 & Odds Ratio (M-H, Random, 95\% Cl) & $0.92[0.59,1.43]$ \\
\hline 1.2 Non-RCT & 4 & 2356 & Odds Ratio (M-H, Random, $95 \% \mathrm{Cl})$ & $0.74[0.53,1.04]$ \\
\hline
\end{tabular}

Analysis 3.1. Comparison 3 Recividism at 24 months: CBT vs control, Outcome 124 months: Proportional.

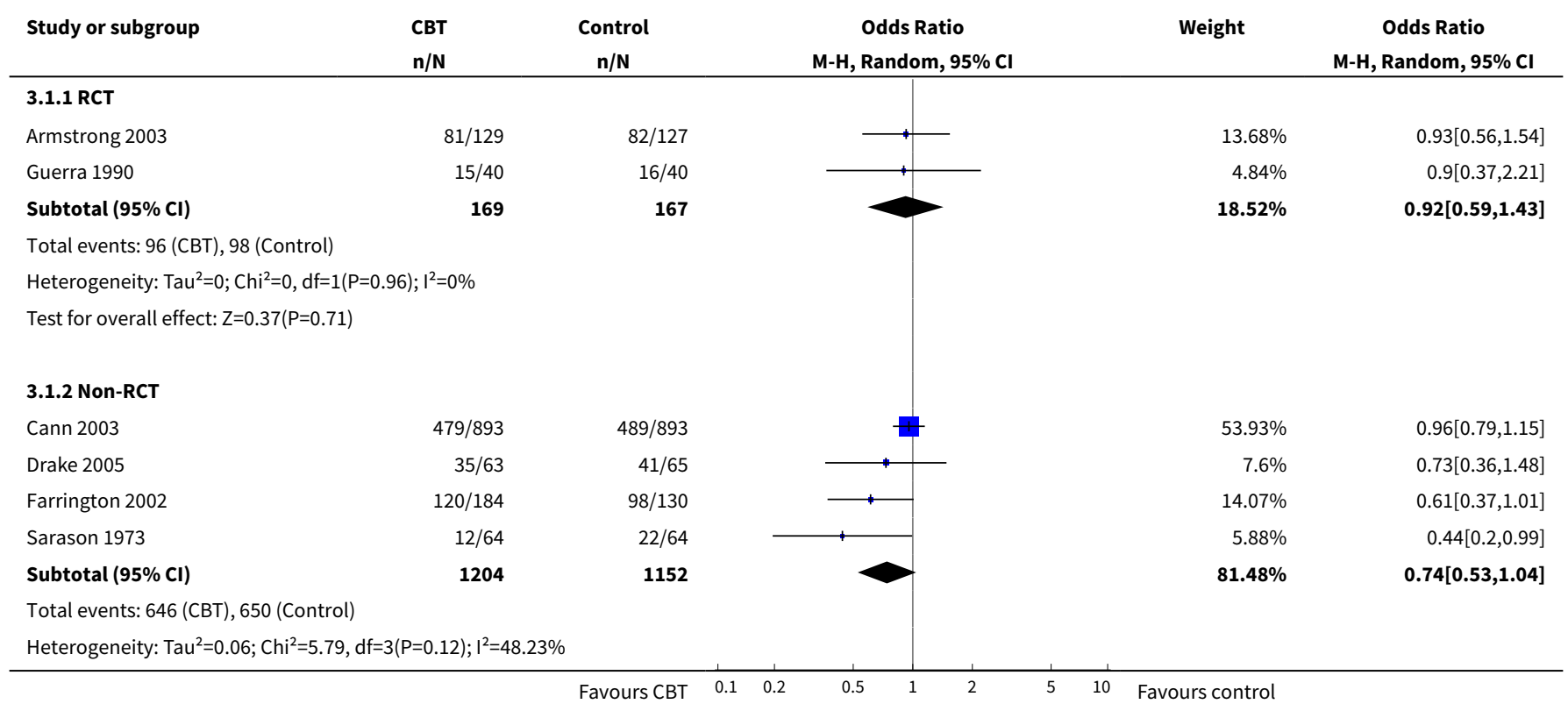




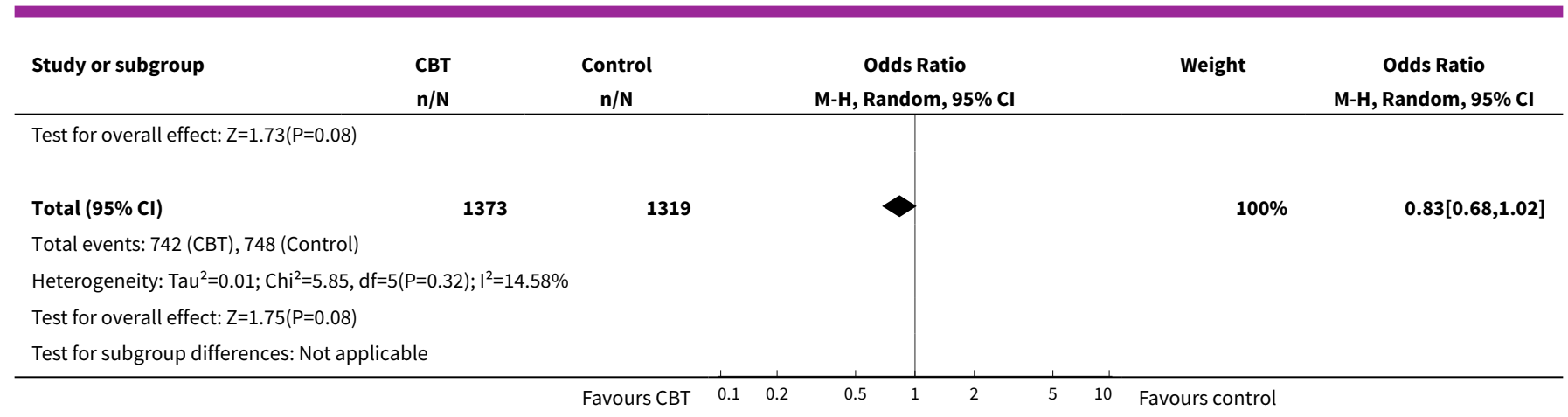

Comparison 4. CBT vs Alternative treatment

\begin{tabular}{lllll}
\hline Outcome or subgroup title & $\begin{array}{l}\text { No. of } \\
\text { studies }\end{array}$ & $\begin{array}{l}\text { No. of } \\
\text { partici- } \\
\text { pants }\end{array}$ & Statistical method & Effect size \\
\hline 1 Alternative treatment Proportional & 3 & & Odds Ratio (M-H, Random, 95\% Cl) & Subtotals only \\
\hline 1.1 Alternative: 12 Months proportional & 2 & 110 & Odds Ratio (M-H, Random, 95\% Cl) & $0.52[0.22,1.22]$ \\
\hline 1.2 Alternative: 24 Months proportional & 2 & 208 & Odds Ratio (M-H, Random, 95\% Cl) & $1.00[0.52,1.92]$ \\
\hline
\end{tabular}

Analysis 4.1. Comparison 4 CBT vs Alternative treatment, Outcome 1 Alternative treatment Proportional.

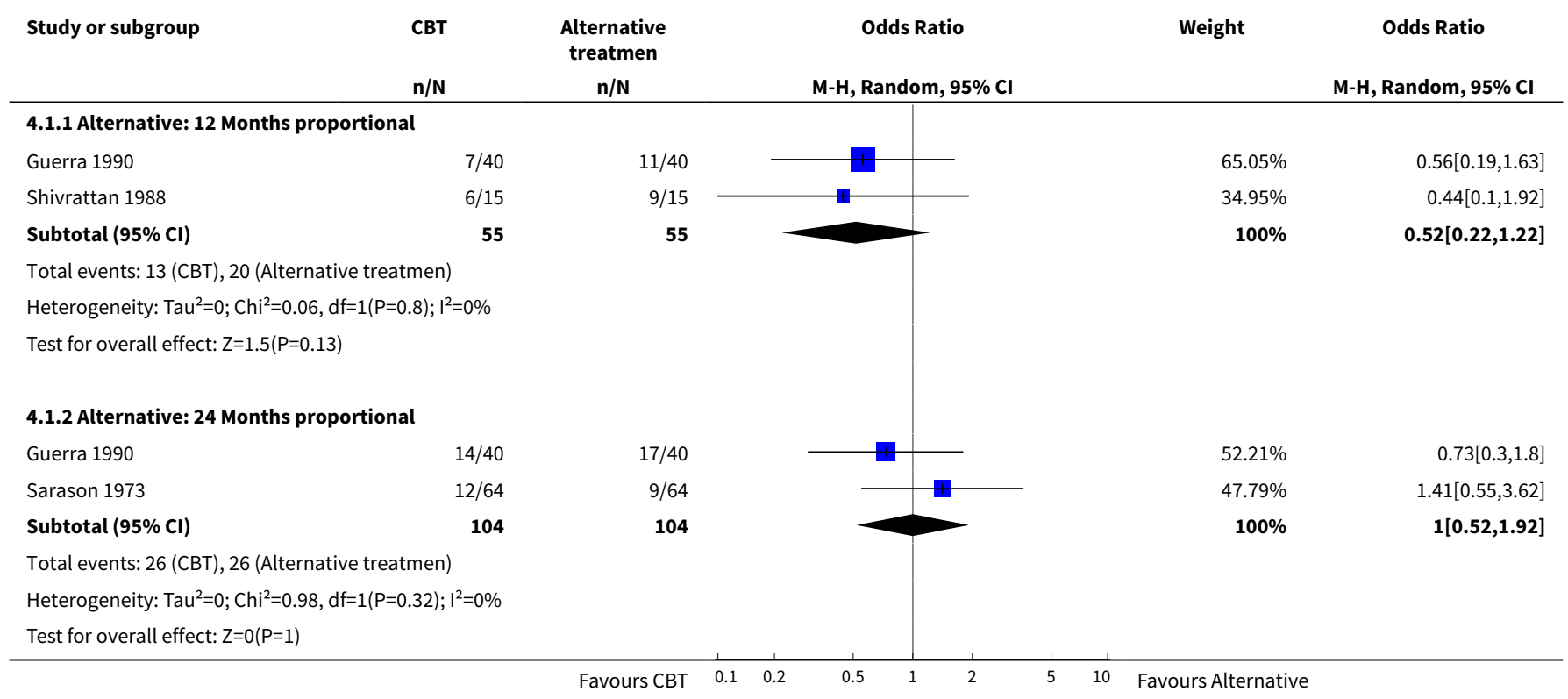

\section{ADDITIONAL TABLES}


Table 1. Additional methods for future updates

\begin{tabular}{ll}
\hline Issue & Method \\
\hline Continuous data & $\begin{array}{l}\text { Continous data will be standardized and 95\% confidence intervals around standardized mean dif- } \\
\text { ferences calculated. }\end{array}$ \\
\hline Subgroup analyses & $\begin{array}{l}\text { Subgroup analyses may be made for interventions with criminogenic focus vs. other foci, for boys } \\
\text { vs. girls and for older vs. younger adolescents }\end{array}$ \\
\hline
\end{tabular}

Table 2. Risk of bias

\begin{tabular}{|c|c|c|c|c|c|c|}
\hline Study & $\begin{array}{l}\text { Selection/Al- } \\
\text { location }\end{array}$ & $\begin{array}{l}\text { Conceal- } \\
\text { ment Alloc }\end{array}$ & $\begin{array}{l}\text { Perfor- } \\
\text { mance }\end{array}$ & Detection & Attrition & $\begin{array}{l}\text { Inten- } \\
\text { tion-to- } \\
\text { treat }\end{array}$ \\
\hline Greenwood & U & M & M & $\mathrm{N}$ & M & $M$ \\
\hline Leeman & $U$ & U & M & $\mathrm{N}$ & $M$ & $M$ \\
\hline Shivrattan & U & U & M & $\mathrm{N}$ & M & M \\
\hline Guerra & U & U & M & $\mathrm{N}$ & $\mathrm{N}$ & $\mathrm{N}$ \\
\hline Drake & $\mathrm{N}$ & N & $M$ & $\mathrm{~N}$ & $M$ & $M$ \\
\hline Bottcher & $\mathrm{N}$ & $\mathrm{N}$ & $M$ & $\mathrm{~N}$ & $M$ & $M$ \\
\hline Deschamps & $N$ & $\mathrm{~N}$ & $M$ & $\mathrm{~N}$ & M & M \\
\hline Farrington & $\mathrm{N}$ & $\mathrm{N}$ & M & $\mathrm{N}$ & $M$ & $M$ \\
\hline Sarason & $U$ & $\mathrm{~N}$ & M & $\mathrm{N}$ & M & M \\
\hline Cann & $\mathrm{N}$ & $\mathrm{N}$ & $M$ & $\mathrm{~N}$ & $M$ & $M$ \\
\hline Armstrong & $U$ & U & $\mathrm{N}$ & $\mathrm{N}$ & U & M \\
\hline Robinson & $\mathrm{N}$ & $\mathrm{N}$ & $M$ & $\mathrm{~N}$ & $\mathrm{~N}$ & $\mathrm{~N}$ \\
\hline
\end{tabular}




\begin{tabular}{|c|c|c|c|c|c|c|c|c|c|c|}
\hline Study & Intended T & Intended C & Actual T & Actual C & $\begin{array}{l}\text { Recidi- } \\
\text { vists } \\
12 \mathrm{~m} \mathrm{~T}\end{array}$ & $\begin{array}{l}\text { Recidi- } \\
\text { vists } \\
12 \mathrm{~m} \mathrm{C}\end{array}$ & $\begin{array}{l}\text { Recidi- } \\
\text { vists } \\
24 \mathrm{~m} \mathrm{~T}\end{array}$ & $\begin{array}{l}\text { Recidi- } \\
\text { vists } \\
24 \mathrm{~m} \mathrm{C}\end{array}$ & \multicolumn{2}{|c|}{ Recidivists $6 \mathrm{~m}$} \\
\hline Greenwood & 75 & 75 & 73 & 75 & 37 & 46 & & & \multicolumn{2}{|c|}{$T=18 ; C=15$} \\
\hline Leeman & 18 & 36 & 20 & 37 & 3 & 15 & & & \multicolumn{2}{|c|}{$T=3 ; C=11$} \\
\hline Shivrattan & 15 & 15 & 13 & 15 & 5 & 9 & & & & \\
\hline Drake & 63 & 65 & 63 & 65 & 31 & 31 & 35 & 41 & & \\
\hline Bottcher & 44 & 38 & 44 & 38 & 35 & 34 & & & & \\
\hline Cann & $1534 ; 24 m=893$ & $1534 ; 24 m=893$ & $1534 ; 24 m=893$ & $\begin{array}{l}1534 \\
24 m=893\end{array}$ & 516 & 545 & 479 & 489 & & \\
\hline Deschamps & 142 & 134 & 134 & 134 & 62 & 77 & & & & \\
\hline Farrington & 184 & 130 & $176 ; 24 m=175$ & 127 & 61 & 70 & 114 & 96 & & \\
\hline Sarason & 64 & 64 & 64 & 64 & & & 12 & 22 & & \\
\hline Guerra & (165) 40 & (165) 40 & 29 & 24 & 5 & 6 & 10 & 11 & & \\
\hline Armstrong & 129 & 127 & 110 & 102 & 59 & 58 & 71 & 72 & $\mathrm{~T}=$ & $=43$ \\
\hline Robinson & $?$ & 70 & 73 & 64 & & & & & $T=$ & $=31$ \\
\hline Study & Intended T & Intended C & & ual T & Actual C & $12 \mathrm{~m}$ & & & $24 \mathrm{~m} \mathrm{~T}$ & $24 \mathrm{mC}$ \\
\hline Shivrattan & 15 & 15 & 1 & & 14 & 5 & 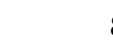 & & & \\
\hline Guerra & (165) 40 & (165) 40 & 2 & & 28 & 5 & 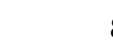 & & 10 & 12 \\
\hline Sarason & 64 & 64 & 6 & & 64 & & & & 12 & 9 \\
\hline
\end{tabular}


Table 5. Participants

\begin{tabular}{|c|c|c|c|c|c|c|}
\hline Study ID & Location & Gender & Age & Ethnicity & Criminal history & Attrition \\
\hline $\begin{array}{l}\text { Arm- } \\
\text { strong } \\
2003\end{array}$ & $\begin{array}{l}\text { USA. Montgomery } \\
\text { County Detention } \\
\text { Center. Incarcerat- } \\
\text { ed youth }\end{array}$ & Male & $15-22$ & $\begin{array}{l}\text { African American 55\%; } \\
\text { Caucasian 32\%; His- } \\
\text { panic 6\%; Asian 7\% }\end{array}$ & $\begin{array}{l}99 \% \text { had been ar- } \\
\text { rested prior to cur- } \\
\text { rent. } 21 \% \text { had four or } \\
\text { more prior arrests }\end{array}$ & None \\
\hline $\begin{array}{l}\text { Bottcher } \\
1985\end{array}$ & $\begin{array}{l}\text { USA, The Athena } \\
\text { program in Fresno. } \\
\text { Secure setting }\end{array}$ & Female & $\begin{array}{l}\text { Age aver- } \\
\text { age was } \\
15 \text { but } \\
\text { a few as } \\
\text { young as } \\
12 .\end{array}$ & $\begin{array}{l}\text { Experimental group: } \\
\text { White } 27 \% \text {; Hispanic } \\
55 \% \text {; Black } 16 \% \text {; Oth- } \\
\text { er } 2 \% \text {. Control group: } \\
\text { White } 34 \% \text {; Hispanic } \\
55 \% \text {; Black } 16 \% \text {; Other } \\
2 \% \text {. }\end{array}$ & $\begin{array}{l}\text { Participants had rel- } \\
\text { atively long prior } \\
\text { records (>7 y) and } \\
\text { fairly serious offens- } \\
\text { es. }\end{array}$ & None \\
\hline Cann 2003 & $\begin{array}{l}\text { England (GB). Pris- } \\
\text { ons }\end{array}$ & Male & $\begin{array}{l}\text { Below } 21 \\
\text { at sen- } \\
\text { tencing }\end{array}$ & Not specified & Not specified & None \\
\hline $\begin{array}{l}\text { De- } \\
\text { schamps } \\
1998\end{array}$ & $\begin{array}{l}\text { Canada, Windsor, } \\
\text { Ontario. Open cus- } \\
\text { tody }\end{array}$ & Male & $16-21$ & Not specified & $\begin{array}{l}\text { Not specified, but } \\
\text { open facility }\end{array}$ & $\begin{array}{l}8 \text { of the } 142 \text { men } \\
\text { treated at the ex- } \\
\text { perimental facility } \\
\text { did not have com- } \\
\text { plete records and } \\
\text { were excluded }\end{array}$ \\
\hline $\begin{array}{l}\text { Drake } \\
2005\end{array}$ & $\begin{array}{l}\text { USA, Washington } \\
\text { state. Detention } \\
\text { center }\end{array}$ & $\begin{array}{l}\text { Experi- } \\
\text { mental } \\
\text { group: } \\
21 \% \text { male: } \\
\text { Control } \\
\text { group: } \\
31 \% \text { male }\end{array}$ & $\begin{array}{l}\text { Experi- } \\
\text { mental } \\
\text { group: } \\
14.7 ; \\
\text { Control } \\
\text { group: } \\
15.1\end{array}$ & $\begin{array}{l}\text { Experimental group: } \\
\text { white } 73 \% \text { : Control } \\
\text { group: white } 60 \% \text {. }\end{array}$ & $\begin{array}{l}\text { Not specified, partici- } \\
\text { pants were criminals } \\
\text { with mental health } \\
\text { problems }\end{array}$ & None \\
\hline $\begin{array}{l}\text { Farring- } \\
\text { ton } 2002\end{array}$ & $\begin{array}{l}\text { England. Military } \\
\text { corrective training } \\
\text { center (open facili- } \\
\text { ty) }\end{array}$ & Male & $18-21$ & $\begin{array}{l}\text { Experimental group: } \\
158 \text { white; } 18 \text { non- } \\
\text { white. Control group: } \\
109 \text { white; } 18 \text { non- } \\
\text { white. }\end{array}$ & $\begin{array}{l}\text { They had to be suit- } \\
\text { able for open condi- } \\
\text { tions but were rela- } \\
\text { tively severe crimi- } \\
\text { nals }\end{array}$ & $\begin{array}{l}11 \text { participants } \\
\text { could not be } \\
\text { found in the reg- } \\
\text { isters leaving } 176 \\
\text { experimental and } \\
127 \text { controls for } \\
\text { follow up with reg- } \\
\text { isters. TOT analy- } \\
\text { sis is based on the } \\
105 \text { experimental } \\
\text { participants who } \\
\text { completed all five } \\
\text { phases. }\end{array}$ \\
\hline $\begin{array}{l}\text { Green- } \\
\text { wood } \\
1993\end{array}$ & $\begin{array}{l}\text { USA, Ohio. No phys- } \\
\text { ical constraints } \\
\text { (training school) }\end{array}$ & Male & $15-17$ & $\begin{array}{l}\text { Experimental group: } \\
\text { white } 60 \% \text {; black } 40 \% \text {. } \\
\text { Control group: white } \\
64 \% \text {; black } 35 \% \text {; other } \\
1 \% .\end{array}$ & $\begin{array}{l}\text { About } 3 \text { prior convic- } \\
\text { tions }\end{array}$ & $\begin{array}{l}2 \text { controls had no } \\
\text { records }\end{array}$ \\
\hline $\begin{array}{l}\text { Guerra } \\
1990\end{array}$ & $\begin{array}{l}\text { USA,California. } \\
\text { Maximum security } \\
\text { correctional facility }\end{array}$ & $\begin{array}{l}\text { Male } 60 \% \\
\text { Female } \\
40 \%\end{array}$ & $15-18$ & $60 \%$ Black or Hispanic & $\begin{array}{l}80 \% \text { at least one ag- } \\
\text { gressive offense }\end{array}$ & $\begin{array}{l}196 \text { eligible, } 171 \\
\text { volunteered, } 165 \\
\text { participated in } \\
\text { pretests, } 126 \text { com- }\end{array}$ \\
\hline
\end{tabular}


Table 5. Participants (Continued)

pleted intervention and posttest.

6 were randomly eliminated and

120 randomized to the trhree groups. 81 of the 120 were possible to trace with recidivism. The remaining 39 were either still in the institution or had left the area and could not be located.

\begin{tabular}{|c|c|c|c|c|c|}
\hline $\begin{array}{l}\text { Leeman } \\
1993\end{array}$ & $\begin{array}{l}\text { USA, Columbus, } \\
\text { Ohio. Medium secu- } \\
\text { rity correctional fa- } \\
\text { cility }\end{array}$ & Male & $15-18$ & $\begin{array}{l}38 \text { Caucasian; } 18 \text { Black; } \\
1 \text { Hispanic }\end{array}$ & $\begin{array}{l}\text { Relatively mild seri- } \\
\text { ous felonies (break- } \\
\text { ing and entering, re- } \\
\text { ceiving stolen prop- } \\
\text { erty and burglary). }\end{array}$ \\
\hline
\end{tabular}

None, (3 replaced because they were erroneously included initially making the total 3 more than intended!)

\begin{tabular}{|c|c|c|c|c|c|c|}
\hline $\begin{array}{l}\text { Sarason } \\
1973\end{array}$ & $\begin{array}{l}\text { USA, Washington. } \\
\text { Juvenile reception } \\
\text { - diagnostic cen- } \\
\text { ter for committed } \\
\text { youth }\end{array}$ & Male & $15-18$ & Not specified & Not specified & None \\
\hline $\begin{array}{l}\text { Shivrattan } \\
1988\end{array}$ & $\begin{array}{l}\text { Canada, Ontario. } \\
\text { Incarcerated at } \\
\text { school }\end{array}$ & Male & $15-17$ & Not specified & Not specified & $\begin{array}{l}45 \text { were random- } \\
\text { ized but recidi- } \\
\text { vism was reported } \\
\text { for } 13,14 \text { and } 15 \text { in } \\
\text { the three groups. }\end{array}$ \\
\hline $\begin{array}{l}\text { Robinson } \\
1994\end{array}$ & $\begin{array}{l}\text { USA, Utah. Secure } \\
\text { facility }\end{array}$ & $\begin{array}{l}\text { Male } 98 \% ; \\
\text { Female } \\
2 \%\end{array}$ & $14-18$ & $\begin{array}{l}64 \% \text { Anglo Americans; } \\
20 \% \text { Hispanic; } 11 \% \\
\text { African Americans; } \\
8 \% \text { Asian; } 1 \% \text { Native } \\
\text { Americans }\end{array}$ & $\begin{array}{l}\text { Around } 2.5 \text { prior } \\
\text { crimes against per- } \\
\text { sons. }\end{array}$ & $\begin{array}{l}73 \text { (in some tables } \\
74 \text { ) in the Experi- } \\
\text { mental group re- } \\
\text { ceived the cur- } \\
\text { riculum. An un- } \\
\text { known numver } \\
\text { of students who } \\
\text { failed to attend } \\
90 \% \text { of the time } \\
\text { or failed the class } \\
\text { were eliminated } \\
\text { from the treat- } \\
\text { ment group. }\end{array}$ \\
\hline
\end{tabular}

WHAT'S NEW

\begin{tabular}{lll}
\hline Date & Event & Description \\
\hline 30 June 2008 & Amended & Converted to new review format. \\
\hline
\end{tabular}




\section{HISTORY}

Protocol first published: Issue 1, 2006

Review first published: Issue 4, 2007

\begin{tabular}{lll}
\hline Date & Event & Description \\
\hline 22 July 2007 & $\begin{array}{l}\text { New citation required and conclusions } \\
\text { have changed }\end{array}$ & Substantive amendment \\
\hline 1 September 2006 & Amended & $\begin{array}{l}\text { Bengt-Årmelius took over as contact reviewer from Tore An- } \\
\text { dreassen. }\end{array}$ \\
\hline
\end{tabular}

\section{CONTRIBUTIONS OF AUTHORS}

Bengt-Åke Armelius (BA) and Tore Andreassen (TA) contributed to writing the text of this review. The search strategy was developed by Joanne Abbott, TSC of the Cochrane Developmental, Psychosocial and Learning Problems Group, and Anette Fomsgaard (AF) of the Nordic Campbell Center. Searches were run by BA, Joanne Abbott and AF.

Selection of abstracts, review of potential trials, data extraction and data entry were independently done by TA and BA. Analyses were performed by BA. The text of the completed systematic review was written by BA. Responsibility for updating the review will be shared between TA and BA.

\section{DECLARATIONS OF INTEREST}

Tore Andreassen is involved in design and implementation of a residential treatment model in Norway based on a non-systematic review of the research. This model includes risk assessment and focus on criminogenic needs.

\section{SOURCES OF SUPPORT}

\section{Internal sources}

- No sources of support supplied

\section{External sources}

- Nordic Campbell Centre, Denmark.

\section{N DEX TERMS}

\section{Medical Subject Headings (MeSH)}

Antisocial Personality Disorder [ ${ }^{*}$ therapy]; Behavior Therapy [methods]; Cognitive Behavioral Therapy [ ${ }^{*}$ methods]; Residential Treatment [*methods]; Secondary Prevention

\section{MeSH check words}

Adolescent; Adult; Female; Humans; Male 